\title{
Inflammation in the COVID-19 airway is due to inhibition of CFTR signaling by the SARS-CoV-2 Spike protein
}

Hung Caohuy 1,2,3 , Ofer Eidelman ${ }^{1,2}$,Tinghua Chen ${ }^{1,2,3}$, Qingfeng Yang ${ }^{1,4}$, Nathan I. Walton $1,2,3$, Harvey B. Pollard ${ }^{1,2,3}$,

1. Department of Anatomy, Physiology and Genetics, Uniformed Services University School of Medicine, Uniformed Services University of the Health Sciences, Bethesda, MD 20814.

2. Collaborative Health Initiative Research Program (CHIRP), Uniformed Services University of the Health Sciences, Bethesda, MD 20814

3. Consortium for Health and Military Performance (CHAMP), Uniformed Services University of the Health Sciences, Bethesda, MD 20814. Uniformed Services University of the Health Sciences, Bethesda, MD 20814

4. Center for the Study of Traumatic Stress (CSTS), and Department of Psychiatry, Uniformed Services University of the Health Sciences, Bethesda, MD 20814

${ }^{*}$ Communications:

Harvey B. Pollard, M.D., Ph.D.

Department of Anatomy, Physiology and Genetics

Uniformed Services University School of Medicine,

Uniformed Services University of the Health Sciences, Bethesda, MD 20814

T: 301-295-3200; Email: harvey.pollard@usuhs.edu 


\begin{abstract}
Background: SARS-CoV-2-contributes to sickness and death in COVID-19 patients partly by inducing a hyper-proinflammatory immune response in the host airway. This hyperproinflammatory state involves activation of signaling by $\mathrm{NF} \kappa \mathrm{B}$ and $\mathrm{ENaC}$, and expression of high levels of cytokines and chemokines. Post-infection inflammation may contribute to "Long COVID", and there are also other long term consequences of acute severe COVID-19, which double or triple the chances of dying from any cause within a year. Enhanced signaling by $\mathrm{NF}_{\kappa} \mathrm{B}$ and $\mathrm{ENaC}$ also marks the airway of patients suffering from cystic fibrosis, a lethal proinflammatory genetic disease due to inactivating mutations in the CFTR gene. We therefore hypothesized that inflammation in the COVID-19 airway might similarly be due to inhibition of CFTR signaling by SARS-CoV-2 Spike protein.

Methods: This hypothesis was tested using the hTERT-transformed BCi-NS1.1 basal stem cell, previously derived from small airway epithelia, which were differentiated into a model of small airway epithelia on an air-liquid-interface (ALI). Cyclic AMP-activated CFTR chloride channel activity was measured using an Ussing Chamber. Cell surface-CFTR was labeled with the impermeant biotin method.

Results: Exposure of differentiated airway epithelia to SARS-CoV-2 Spike protein resulted in loss of CFTR protein expression. As hypothesized, TNF $\alpha / N F \kappa B$ signaling was activated, based on increased protein expression of TRADD, the first intracellular adaptor for the TNF $\alpha / T N F R 1$ complex, TNFR1, the TNF $\alpha$ receptor, phosphorylated $I_{\kappa} B \alpha$, and the chemokine IL8. ENaC activity was also activated, based on specific changes in molecular weights for $\alpha$ and $\gamma \mathrm{ENaC}$. Exposure of the epithelia to viral Spike protein suppressed cAMP-activated CFTR chloride channel activity. However, addition of $30 \mathrm{nM}$ concentrations of cardiac glycoside drugs ouabain, digitoxin and digoxin, prevented loss of channel activity. ACE2 and CFTR were found to coimmunoprecipitate (co-IP) in both basal cells and epithelia, suggesting that the mechanism for Spike-dependent CFTR loss might involve ACE2 as a bridge between Spike and CFTR. In addition, Spike exposure to the epithelia resulted in failure of endosomal recycling to return CFTR to the plasma membrane, suggesting that failure of CFTR recovery from endosomal recycling might be a mechanism for Spike-dependent loss of CFTR.

Conclusion: Based on experiments with this model of small airway epithelia, we predict that inflammation in the COVID-19 airway may be mediated by inhibition of CFTR signaling by SARSCoV-2 Spike protein, thus inducing a CFTR-null, cystic fibrosis-like clinical phenotype. Descriptions of COVID-19 in CF carriers with only one copy of wildtype CFTR suggest that this model-based conclusion might be consistent with patient-based experience.
\end{abstract}




\section{Introduction}

SARS-CoV-2-contributes to sickness and death in COVID-19 patients partly by inducing a hyper-proinflammatory immune response in the host airway [1, 2]. Consistently, COVID-19 patients who have been admitted to the Intensive Care Unit (ICU) have the most severe forms of inflammatory disease [3]. This hyper-proinflammatory state, also termed cytokine storm [4], or cytokine release syndrome [5], involves activation of signaling by $\mathrm{NF} \kappa \mathrm{B}[6,7]$ and by $\mathrm{ENaC}$, the Epithelial Sodium channel $[8,9]$. Sustained, post infection inflammation may also contribute to Post-Acute Sequelae of COVID-19 (PASC), also termed "long COVID" [10-12], and to acute "Severe COVID-19", which doubles or triples the chances of dying from any cause within a 6-12 month period $[13,14]$. However beyond the specific involvement of NFKB and ENaC in COVID19, the actual mechanisms remain poorly understood. $N F \kappa B$, the master regulator of inflammation, contributes to cytokine storm by driving the synthesis and secretion of cytokines and chemokines [15]. In response to NFKB activation the COVID-19 airway responds to IL-8 and other cytokines by attracting high levels of neutrophils [16], and changes in other types of immune cells $[16,17]$. Activation of $\mathrm{ENaC}$ in the airway also contributes to inflammation, as well as to airway surface dehydration and impaired mucociliary clearance $[9,18,19]$. SARS-CoV-2 infection is initiated by the viral Spike protein binding to the cellular receptor ACE2. However it remains to be better understood how inflammation follows from this interaction. We have recently reported that nanomolar concentrations of cardiac glycosides such as ouabain, digitoxin and digoxin competitively inhibit binding of the SARS-CoV-2 Spike protein to the ACE2 receptor [20]. Consequently they also block both penetration by Spike-pseudotyped virus and infectivity by native SARS-CoV-2 in human lung cells [20]. Thus these candidate anti-viral drugs could additionally serve as tools to help elucidate the virus-specific pro-inflammatory mechanisms.

Coincident activation of both $\mathrm{NF} \kappa \mathrm{B}$ and $\mathrm{ENaC}$ in the airway is a characteristic of cystic fibrosis (CF), a common, lethal, autosomal recessive genetic disease. In this case the proinflammatory activation mechanisms for both $\mathrm{NF \kappa B}$ and $\mathrm{ENaC}$ depend on the presence of inactivating mutations in the CF protein CFTR [9, 21-24]. Under resting conditions, CFTR sends constitutively synthesized TRADD, the first intracellular adaptor of the TNF $\alpha / T N F R 1$ complex, to the proteosome [25] (see also Supplemental Figure S1). Without TRADD activation, the TNF $\alpha / N F \kappa B$ signaling pathway is silent and NF $\kappa B$ p65 remains inactively complexed with $I_{\kappa} B \alpha$ in the cytosol. However, in the absence of CFTR, TRADD survives in the cytosol to signal to the 
$\mathrm{IKK} \alpha, \beta, \gamma$ complex to phosphorylate $\mathrm{I}_{\kappa \mathrm{B}} \alpha$ and send $\mathrm{p}-\mathrm{I}_{\kappa} \mathrm{B} \alpha$ to the proteosome. NF $\kappa \mathrm{B}, \mathrm{p} 65$ is thus freed to enter the nucleus and to drive proinflammatory cytokine and chemokine expression. Similarly, although by a less well understood mechanism, CFTR constitutively suppresses ENAC activity in the lung [26, 27]. Because activated ENaC removes sodium from the airway, the purpose of this suppression mechanism is understood to ensure adequate hydration of the airway. In response to active $\mathrm{Cl}$ - conductance by the cAMP-activated CFTR chloride channel, $\mathrm{Na}+$ is passively conducted into the airway through inactive ENaC channels. Water is then passively moved into the airway in response to the resulting osmotic gradient. However, in the absence of CFTR-mediated chloride movement into the airway, ENaC is proteolytically activated by TMPRSS2 and FURIN. The now activated ENaC channel uncontrollably dehydrates the airway by removing sodium from the airway and expelling it through the basolateral part of the cell [2729]. The airway responds to this dehydration damage with $N F \kappa B$-dependent inflammation, including activation of the NLRP inflammasome and cytokines such as IL-18, IL-1 $\beta$ and caspase 1 [30]. ENaC in the lung is simultaneously activatedby Angiotensin II which is synthesized in the lung by ACE in the pulmonary vasculature, and inactivated by epithelial ACE2 [31, 32] (see Supplemental Figure S1). Conceptually, these interactions are part of a massive CFTR interaction network, which was first understood from the viewpoint of interlocking PDZ-based molecular switches [33]. Later the CFTR network was identified with multiple molecular chaperones and other functional proteins [34, 35]. More recently the CFTR network has been identified in terms of a complex set of multidimensional systems biology-based interactive maps for wildtype and mutant CFTR [24]. Thus CFTR is a key regulator of airway hydration and control of proinflammatory TNF $\alpha / N F \kappa B$ and $E N a C$ signaling.

Based on this close proinflammatory relationship in the airway between COVID-19 and CF symptoms, and by support from preliminary data, we have hypothesized that inflammation in the COVID-19 airway might be due to inhibition of CFTR signaling by the SARS-CoV-2 Spike protein. However, there has been conflicting data regarding the role of the viral Spike protein in driving proinflammatory signaling in cultured cells [36, 37]. Therefore as a more physiological platform to test this hypothesis we used the hTERT-transformed BCi-NS1.1 basal stem cell, isolated from the small airways epithelium, which we studied in differentiated form as a model airway epithelium at the air-liquid-interface (ALI) [38-40]. Attractive features of this model epithelium include (i) histologic and molecular fidelity to normal small airway epithelial cell physiology [38, 39]; (ii) a normal male karyotype, 46,X/Y [38-40]; (iii) cell-specific expression of COVID-19 related genes including ACE2, ADAM 10 and ADAM 17, TMPRSS2, FURIN, and CTSL 
[38]; and (iv) expression of CFTR protein by both basal cells and the differentiated epithelia (our preliminary data). To test the hypothesis we have asked whether exposure of the differentiated epithelium to SARS-CoV-2 Spike protein (1) activates critical parts of the TNF $\alpha / N F \kappa B$ and ENaC signaling pathways; (2) induces loss of CFTR protein and cAMP-activated CFTR chloride channel activity; (3) rescues loss of CFTR channels by the cardiac glycoside drugs, ouabain, digitoxin and digoxin; and (4) suppresses CFTR levels by inhibiting endosomal recycling of CFTR. We also tested whether (5) epithelial ACE2 binds to CFTR. We found positive answers to all five tests, and concluded that the origins of the proinflammatory COVID-19 airway may be traced in part to the ability of the Spike protein to induce an approximately CFTR-null phenotype in the virus infected lung. To our knowledge this is the first time COVID-19 airway inflammation has been experimentally traced to a contribution from SARS-CoV-2 Spike-dependent inhibition of CFTR signaling.

\section{Results}

\section{$\underline{\text { SARS-CoV-2 Spike protein activates TNF } \alpha / N_{K} B \text { signaling in airway epithelium }}$}

As described above, CFTR tonically blocks activation of the TNF $\alpha / N F \kappa B$ signaling

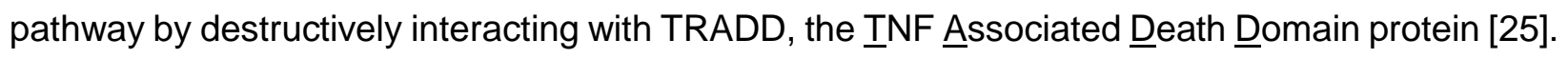
Therefore, to determine whether the inhibitory CFTR/TRADD interaction is reduced in Spiketreated epithelia, we tested whether expression of TRADD was increased when epithelia were exposed to the Spike protein from the original strain of SARS-CoV-2 isolated in 2019 in Wuhan, China (Original-[S1S2] Spike). In parallel we also tested whether other proteins in the TNF $\alpha / N F \kappa B$ signaling pathway, such as TNFR1, $p-I_{\kappa} B \alpha$ and the chemokine IL-8, were also increased. Figure 1a shows that as Spike protein increases, so do the protein expressions for TRADD, TNFR1 and $\mathrm{p}-\mathrm{I}_{\kappa} \mathrm{B} \alpha$. Figure $\mathbf{1 b}$ also shows that IL-8, as measured in the liquid subphase, increases in proportion to increases in Spike protein concentrations applied to the epithelia. Thus the entire proinflammatoryTNF $\alpha / N F \kappa B$ signaling pathway, including TRADD, is activated by the Spike protein. Inasmuch as TRADD is increased by Spike exposure, it is therefore possible that loss of CFTR function could be involved in the Spike-dependent activation of proinflammatory TNF $\alpha / N F_{\kappa} B$ signaling in airway epithelia.

$\underline{\text { Spike protein reduces CFTR chloride channel activity in differentiated airway epithelia. }}$ 
To test whether Spike proteins affect CFTR channel function, we analyzed Spike-treated epithelia with the Ussing Chamber method. Figure 2a shows that under control conditions, cAMP-activated CFTR chloride channels can be detected, and can be specifically blocked by the

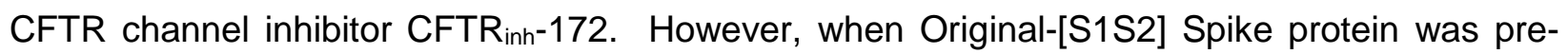
incubated for four hours at the apical surface of the differentiated epithelial culture, CFTR channel activity was significantly and dose-dependently reduced when assayed 20 hours later. The inhibition constant $(\mathrm{Ki})$ is $446 \mathrm{ng} / \mathrm{ml}$ for the Original-[S1S2] Spike protein (see Table 1).

To test for the specificity of the Spike effect, we replaced the Original-[S1S2] Spike protein in the assay with the higher affinity $\beta-1.315$ [S1S2] Spike protein. As shown in Figure $\mathbf{2 b}$, the $\beta$ 1.315 [S1S2] Spike also reduced CFTR channel activity. However, the inhibition constant is 210 $\mathrm{ng} / \mathrm{ml}$ for the $\beta-1.315$ [S1S2] Spike protein, or 47\% lower than for the Original-[S1S2] Spike protein (see Table 1). These [S1S2] Spike proteins also differ in their affinity, or KD, for ACE2. Table 1 and Supplemental Figure S2 show that the KD for ACE2 binding to the Original-[S1S2] Spike is $318 \mathrm{ng} / \mathrm{ml}$ ACE2, as compared with $147 \mathrm{ng} / \mathrm{ml}$ ACE2 for binding to the $\beta-1.315$ [S1S2] Spike. This 47\% reduction for Spike binding parallels the approximately $45 \%$ lower KD value for ACE2 binding to the $\beta-1.315$ [S1S2] Spike protein. These data thus indicate that the relative KD values for Original- and $\beta-1.315$ Spike variants for inhibiting Channel activity and their respective affinities for ACE2 are very similar. A possible interpretation is that the Spike proteins first bind to ACE2, and that the Spike:ACE2 complex may affect consequent CFTR function.

\section{Cardiac glycoside drugs block Spike-dependent loss of CFTR channel activity}

Cardiac glycosides such as ouabain, digitoxin and digoxin have been shown to be potent competitive inhibitors of ACE2 binding to the SARS-CoV-2 Spike protein [20]. The proportional changes in CFTR channel inhibition constants for Original-[S1S1] Spike and $\beta-1.315$ [S1S2] Spike proteins, and respective binding constants to ACE2, suggest that CFTR channel reduction might be initiated by Spike proteins binding to ACE2 (see Table 1). If this suggestion were correct then we could predict that the cardiac glycosides should block Spike-induced reduction in CFTR channel activity. As predicted, Figure 3 a shows that $30 \mathrm{nM}$ concentrations of each cardiac glycoside protects CFTR channels from reduction when epithelia are incubated with Original[S1S2] Spike proteins. Further, Figure $\mathbf{3 b}$ reveal an apparent activity series of [ouabain, digitoxin > digoxin], which is similar to that reported for relative potencies as blockers of Spike:ACE2 binding [20]. Based on both kinetic data and the use of cardiac glycosides as a tool to identify 
Spike:ACE2 binding, it is increasingly likely that a direct Spike interaction with ACE2 is initially responsible for loss of CFTR channel activity.

Spike protein reduces CFTR protein expression in differentiated airway epithelia.

Scrutiny of the CFTR gels in Figure $\mathbf{3 b}$ reveals that exposure of the differentiated epithelia to Spike proteins appears to reduce the total CFTR in the system (see Figure 3 legend for details). To test whether Spike-dependent loss of CFTR chloride channel activity might be due to loss of CFTR protein we examined the consequences of titrating both Original-[S1S2] Spike and $\beta-1.315$ [S1S2] Spike proteins on levels of total epithelial CFTR. Figure $\mathbf{4 a}$ and $\mathbf{b}$ show that both spike strains reduce total CFTR. However, the $\beta-1.315$ [S1S2] Spike protein appears to be the more potent. By comparing these data with those in Figures $\mathbf{2 a}$ and $\mathbf{b}$, we noted that the patterns of reduction as a function of titrations of both Original and $\beta$ spike proteins were remarkably similar to those for suppression of the CAMP-activated CFTR chloride channel. The $K_{i}$ values for Original[S1S2] Spike and $\beta-1.315$ [S1S2] Spike proteins, respectively, are $399 \mathrm{ng} / \mathrm{ml}$ and $193 \mathrm{ng} / \mathrm{ml}$. The $\mathrm{K}_{\mathrm{i}}$ value for $\beta-1.315$ [S1S2] Spike protein is thus reduced relative to the Original-[S1S2] Spike protein by $48 \%$ (see Table 1). The calculations of the kinetic values for CFTR channel and protein are shown in Figure 5 and are summarized in Table 1. The loss of CFTR channels may therefore be due to primary loss of CFTR protein.

$\underline{\text { CFTR co-immunoprecipitates with ACE2 in basal (b-BCi) cells and differentiated (d-BCi) epithelia }}$

A critical question is how Spike proteins affect CFTR survival in epithelia when they must first bind to ACE2. One possibility is that ACE2 might serve as a physical bridge between the Spike protein and CFTR. To test this possibility, we asked whether CFTR and ACE2 could coimmunoprecipitate with each other. Figure 6a shows that both basal cells and differentiated epithelia contain ACE2 and CFTR. ACE2 has been previously reported to be in these basal cells, and it has been previously noted in native airways that aside from infrequent ionocytes, basal cells are second only to secretory cells in CFTR content [41]. Figure 6 b shows that if ACE2 were first immunoprecipitated from either basal cells or epithelia, both immunoprecipitates would contain CFTR. Thus the possibility of ACE2 being a physical bridge, direct or indirect, between Spike protein and CFTR cannot be excluded.

Spike protein inhibits CFTR recovery from endosomal recycling. 
If the binding of spike protein to ACE2 were a necessary precursor to the Spike-induced loss of CFTR from the plasma membrane, the next critical question would be how CFTR was physically removed and destroyed. Under normal conditions, CFTR on the plasma membrane is subject to constitutive endosomal recycling in which misfolded or otherwise damaged CFTR is diverted for destruction to the lysosome (see Supplemental Figure S3). By this mechanism approximately $33 \%$ of damaged or misfolded CFTR is lost to the lysosome in 10 minutes, while the remaining $67 \%$ is returned to the apical plasma membrane [42]. To test whether spikeinduced loss of apical CFTR was due to failure of recovery from endosomal recycling, we used an impermeant biotin labelling method to ask how much CFTR from the apical surface is returned to the apical surface after exposure to progressively increasing concentrations of Original-[S1S2] Spike protein. Figure 7 shows that as the concentration of Original-[S1S2] Spike increases there is a steady reduction in recovery of recycled CFTR. This mechanism for CFTR loss due to exposure to Spike protein is thus consistent with failure of endosomal recycling to return initially apical CFTR to the apical plasma membrane. It is therefore possible that when Spike protein binds to the ACE2:CFTR complex, the bound CFTR may become marked as "damaged " and thus directed to the lysosome.

$\underline{\text { Spike protein induces proteolytic activation of } \mathrm{ENaC}}$

Activation of ENaC occurs when the constitutive inhibitory activity of CFTR is lost, and sodium conductance is activated by proteolytic cleavage of the $\alpha$ and $\gamma$ chains of the heterotrimeric ENaC channel $[9,18,19]$. TMPRSS2, FURIN and possibly other serine proteases are responsible $[43,44]$. To test whether Spike protein treatment could activate ENaC, we asked whether proteolytic fragments of activated $\mathrm{ENaC}$ subunits could be detected following treatment of differentiated epithelial cells with Spike Protein. Figure 8 shows that over the 20 hour period following the 4 hour exposure to Spike proteins, specific proteolytic fragments are detected for both $\alpha \mathrm{ENaC}$ and $\gamma \mathrm{ENaC}$. Furthermore, additional $\gamma \mathrm{ENaC}$ appears to have been synthesized and activated. We conclude that Spike-dependent loss of CFTR is accompanied by proteolytic activation of both $\alpha \mathrm{ENaC}$ and $\gamma \mathrm{ENaC}$.

\section{Discussion}

The mechanism for the proinflammatory phenotype of the COVID-19 airway has been an unsolved puzzle since the earliest days of the pandemic. Here we have used a model human small airway epithelium as an experimental platform, and from the data we are able to predict that 
inflammation in the COVID-19 airway may be due to SARS-CoV-2 Spike-dependent inhibition of CFTR protein expression. We find that ACE2 co-immunoprecipitates with CFTR, suggesting that ACE2 may be the link between Spike protein and CFTR. We also find that loss of CFTR protein can be traced to inability to recover plasma membrane-localized CFTR from the endocytic recycling process. Since the purpose of endocytic recycling is to eliminate damaged proteins, it is likely that the Spike protein, acting through ACE2, confers some form of damage or instability on the CFTR. Kinetic analysis suggests that the mechanism for Spike-dependent elimination of CFTR might depend on Spike first binding to ACE2. Consistently, the cardiac glycoside drugs ouabain, digitoxin and digoxin, which are competitive inhibitors of Spike protein binding to ACE2 [20], are able to rescue Spike-induced loss of cAMP-activated CFTR channel activity. From the perspective of inflammation, the loss of CFTR increased TNF $\alpha / N F \kappa B$ signaling, as indicated by increases in TRADD. This is accompanied by increases in phosphorylated $I_{\kappa} \mathrm{B} \alpha$, and the chemokine IL-8. Additionally, the loss of CFTR resulted in proteolytic activation of both $\alpha$ and $\gamma$ ENaC. These affected pathways are depicted schematically in Supplemental Figure S1. To our knowledge this is the first time COVID-19 airway inflammation has been experimentally traced to a contribution from SARS-CoV-2 Spike-dependent inhibition of CFTR signaling. This insight may have therapeutic implications since the cardiac glycosides, especially digitoxin and ouabain, are able to rescue CFTR channel activity from Spike-induced loss.

In support of possible therapeutic implications of the findings summarized above, a reasonable question might be to what extent a reduction in CFTR expression in the lung, or elsewhere in CF-affected tissues, might relate in any way to COVID-19 disease in humans. One possibility would be to consider the parents of children with CF. Since CF is an autosomal recessive disease, these parents, also termed CF carriers, carry one mutant CFTR gene and one wildtype CFTR gene. The mutant CFTR gene does not contribute any CFTR protein. Unfortunately, the single wildtype gene in CF carriers does not compensate for the loss of the mutant CFTR gene. Consequently CF carriers suffer from reduction in CFTR function by approximately $50 \%[45,46]$. Furthermore, recent large scale studies of CF carriers in Denmark [47] and the United States [48] show that CF carriers have a high risk of CF-related comorbidities, including respiratory tract infections, pancreatitis, hepatitis and others. CF carriers would thus appear to have a narrow functional window with respect to CFTR. It is therefore consistent with our results that in a recent study from the University of Siena, a cohort of hospitalized adult CF carriers with COVID-19 were reported to be more likely than non-CF carriers to develop a form of COVID-19 characterized by acute respiratory distress syndrome, high inflammatory response and early mortality by day 14 [49]. The analysis included an adjustment age, sex and comorbidities. 
Thus a reduction of CFTR in airway cells is a potent risk factor for adverse outcomes in COVID19 disease. The investigators speculated that "Detangling the role of CFTR in COVID-19 pathogenesis would sure(ly) help to better understand such (a) deadly disease”. Based on our results, it is also possible that exposure of airway cells in CF carriers to SARS-CoV-2 Spike protein may make residual wildtype CFTR protein even lower, thus contributing to an even worse outcome for CF carriers with COVID-19.

Additional therapeutic implications are also implicit in the newly described ability of nanomolar concentrations of cardiac glycoside drugs to competitively inhibit Spike:ACE2 binding, and thus to block infectivity of lung cells by native SARS-CoV-2 .[20]. Although COVID-19 is a lethal disease, drug safety remains an issue for consideration. Fortunately these drugs have been in human use since at least 1776, so much is known about them [50]. For example, there are upper concentration limits when treating cardiac patients with these drugs who suffer from heart failure or arrhythmias. Thus for patients in this category these drugs are said to have a narrow therapeutic index [51]. However, for the vast majority of patients with normal hearts, ingestion "... of large but not lethal quantities of digitalis, either in an attempt at suicide or by accident, premature impulses and rapid arrhythmias are infrequent." [51]. Consistently, no drug-related adverse events have been reported in trials on subjects with normal hearts who were given clinical doses of ouabain [52, 53], digitoxin [23, 54], or digoxin [55-58]. Nonetheless, it is important that treatment with these drugs should always be under the control of health care professionals.

Under normal conditions, ENaC activation in the lung is believed to be positively controlled by Angiotensin II, and negatively controlled by Angiotensin (1-7). Inversely, the presence of CFTR negatively controls ENaC in airway epithelial cells, while the absence of CFTR activates ENaC channels (see Supplemental Figure S1). ACE in the lung pulmonary vasculature converts Angiotensin I to Angiotensin II, the principal Renin-Angiotensin-Aldosterone System (RAAS) effector peptide, not only for the lung but for the entire circulation [31]. Angiotensin II can then directly activate pulmonary $E N a C$, via the $A T_{1}$ receptor, or inhibit pulmonary $E N a C$ via the $A T_{2}$ receptor [32, 59]. However, angiotensin II is also inactivated by ACE2 on airway epithelial cells where the Angiotensin (1-7) product inhibits pulmonary ENaC via MSR and the AT2 receptor (see Supplemental Figure S1). There is thus a balance struck by ACE and ACE2 to regulate Angiotensin II concentration and therefore ENaC activity in the lung. On the other hand, CFTR appears to control passive $\mathrm{ENaC}$ activity by transporting negative chloride ions into the airway. To compensate for high levels of negative chloride ions in the airway, positive sodium ions enter 
the airway passively through the inactive $\mathrm{ENaC}$ channel. Together the $\mathrm{Na}^{+}$and $\mathrm{Cl}^{-}$ions passively draw water into the airway $[43,60,61]$. ENaC is located mostly on ciliary cells in the lung, while CFTR is mostly expressed in secretory cells [62]. Thus the need to compensate for excess negative charge in the airway may be the most likely basis for physiological control of the passive ENaC contribution to airway hydration. The physiological consequence is a dynamic and responsive hydration process which helps to maintain the paraciliary fluid layer upon which mucins are propelled upward by cilia to either be expectorated or swallowed [60]. However, in the absence of functional CFTR, either by mutation or by Spike-dependent loss, ENaC is activated by serine proteases, including TMPRSS2 and FURIN [8, 63, 64]. Excessive sodium absorption ensues: dehydrating the airway; disrupting mucociliary clearance; and activating inflammation [9, $18,19,43]$.

It is at this point that the mechanisms of ENaC activation and the mechanism of viral invasion of airway epithelial cells by SARS-CoV-2 intersect [8]. For the virus to gain entry into the epithelial cell in the lung, the viral [S1S2] SARS-CoV-2 Spike protein binds to ACE2. The Spike protein is then further proteolytically cleaved at the [S1S2] junction into the [S1 + S2] Spike protein by TMPRSS2, FURIN, and possibly other serine proteases [65, 66] (see Figure 8 and Supplemental Figure S1). These proteolytic events are thus key to viral infectivity and development of COVID-19. Coincidentally these same proteases are evolutionarily located at the apical membrane surface for the physiological purpose of proteolytically activating the $\alpha$ and $\gamma$ subunits of the heterotrimeric ENaC channel. It has been speculated that the SARS-CoV-2 virus has taken advantage of this existing protease system by evolving a CendR amino acid sequence at the S1S2 junction on the Spike protein that enables the existing TMPRSS2 and FURIN to drive infectivity [8]. The BCi-NS1.1 basal cells and differentiated epithelia both contain high levels of TMPRSS2 and FURIN [38], and the coincidence of these two processes in the epithelial culture is manifest by the Spike-dependent proteolytic activation of $\alpha$ and $\gamma \mathrm{ENaC}$, as shown in Figure 8.

Following the findings that ACE2 co-immunoprecipitates with CFTR, and that addition of Spike protein causes dose-dependent loss of CFTR, we speculated that Spike must first bind to ACE2 in order to affect CFTR loss. However, the problem was how to test this possibility directly. As an indirect solution we tested whether [S1S2] Spike proteins with different affinities for ACE2 might have proportional abilities to reduce both cAMP-activated CFTR chloride channel activity and CFTR protein expression. As summarized in Table 1 the loss of the CFTR protein itself, and of its channel function seemed to be dependent on the relative potencies of both the Original- and 
$\beta$-1.315 Spike proteins for ACE2 binding. As a more direct test we asked whether the cardiac glycoside drugs would prevent loss of CFTR channel and protein. Conclusively, $30 \mathrm{nM}$ concentrations of these drugs nearly completely blocked Spike-induced loss of CFTR channel activity (see Figure $3 \mathbf{b}$ ). We conclude that these kinetic and pharmacological data are evidence that the [S1S2] Spike protein most likely first binds to ACE2 in order to effect loss of CFTR protein and function.

It is important to mention here that induced loss of CFTR by environmental or infectious agents has been observed in the past. For example, Chronic Obstructive Pulmonary Disease (COPD) is associated with smoke-induced, sustained loss of CFTR [67-70]. Reduced CFTR mRNA levels are also seen in scrape biopsies from nasal epithelia of COPD patients [67, 71]. The agent affecting CFTR in cigarette smoke has been identified as acrolein, which inhibits CFTR chloride channel gating, not only in the lung but also in the intestine [72]. A second example is infection of HEK-293 cells by influenza strain A/Udorn, which has been reported to reduce CFTR chloride channel activity and CFTR protein [73, 74]. The viral matrix protein M2 has been proposed to promote intracellular lysosomal degradation of CFTR, although the biochemical mechanism is not well understood. These examples thus suggest a similarity of disease states in which the CFTR protein is diminished by an external factor rather than a classical mutation. Thus the reducing effect of SARS-CoV-2 Spike protein on CFTR could be a third example.

This study has limitations. First, it is a limitation of our study that we do not yet understand how ACE2 binds to CFTR. Nonetheless, we know experimentally that they do bind together, both in epithelia and in basal cells. Second, it is a limitation that we do not yet understand the nature of the apparent damage or instability inflicted on CFTR by the Spike:ACE2:CFTR interaction. Nonetheless, the classical impermeant biotin experiment indicates this must happen. Third, we do not yet know which cells in the model epithelia are experimentally responsible for the CFTR and ACE2 activities. However, the basal cells possess both ACE2 and CFTR and share some activities with the epithelia. Furthermore, secretory cells, which dominate airway CFTR expression in native superficial epithelia [75], are present in the differentiated BCi-NS1.1 epithelia [39], as is ACE2 [38]. We suggest that substantively addressing these questions would be clearly beyond the experimental scope of the present study and look forward to addressing them in the future.

Conclusion: 
Based on these investigations with a model of small airway epithelia we predict that increased TNF $\alpha / N F K B$ - and ENaC-dependent inflammation in the COVID-19 airway is mediated by inhibition of CFTR signaling by SARS-CoV-2 Spike protein, thus inducing a pro-inflammatory CFTR-null clinical phenotype in lung epithelia. Based on descriptions of more severe COVID-19 in adult CF carriers with only one copy of wildtype CFTR we suggest that this model-based conclusion may be consistent with patient-based experience.

\section{Methods}

\section{$\underline{\text { Cells and culture conditions }}$}

As a cellular platform for the study we have used the hTERT-transformed BCi-NS1.1 basal stem cell differentiated on the air-liquid-interface (ALI) [38, 39]. We thank Dr. R.G. Crystal (Cornell Medical College, New York City, NY) for the gift of the cells. The cells used here came as Passage 11 following original derivation. The serum-free culture medium was used directly as indicated (Walters et al, 2013). Differentiation in the ALI was conducted over a 25 day period exactly as described [39]. Cyclic AMP-activated CFTR chloride channel activity was measured using a Ussing Chamber as previously described [23].

\section{Co-immunoprecipitation of ACE2 and CFTR}

At the end of an experiment media were removed; epithelia or cells were washed with PBS; and then lysed in RIPA buffer containing protease and phosphatase inhibitors. Total lysates were precleared with Protein A Dynabeads (Thermo Scientific), incubated for $24 \mathrm{hr}$ at $4^{\circ} \mathrm{C}$ with 2 $\mu \mathrm{g}$ of normal rabbit serum (NRS) or rabbit anti-ACE2 antibody (proteintech), and finally incubated for $4 \mathrm{hr}$ with Protein A Dynabeads. CFTR in the immuno-precipitated protein complexes was analyzed by western blotting using anti-CFTR antibodies, clones UNC 570 and UNC 660, development of which were which were funded by the Cystic Fibrosis Foundation, and purchased by us from the University of North Carolina, Chapel Hill, NC). See [21] for further details.

Electrophysiology of epithelial cultures at the air-liquid-interface (ALI).

Human hTERT-transformed BCi-NS1.1 basal stem cells were seeded at a concentration of $4.5 \times 10^{5}$ cells $/ \mathrm{cm}^{2}$ on Transwell inserts ( $0.4 \mathrm{~mm}$ size pore; Corning Inc, NY) and differentiated at the air-water interface for 25 days [39]. Cells were exposed to different concentrations of Spike protein for 4 hours, washed with fresh medium, and then incubated for a further 24 hours. 
Snapwell inserts were mounted in Ussing Chambers (Physiologic Instruments, Reno Nevada). A basolateral-to-apical chloride gradient was imposed by partially replacing $\mathrm{NaCl}$ with $\mathrm{NaGluconate.}$ The epithelium was voltage clamped and short-circuit current $\left(I_{s c}\right)$ was measured. CFTR channel activity was detected by first inactivating sodium currents with $100 \mu \mathrm{M}$ amiloride; then activating CFTR chloride channels with $10 \mu \mathrm{M}$ forskolin and $100 \mu \mathrm{M}$ IBMX; then specifically inactivating CFTR channels with $10 \mu \mathrm{M}$ CFTRinh-172. See $[23,76]$ for further details.

\section{Measurement of ACE2 and CFTR endosomal recycling}

Apical surfaces of epithelia were treated with different concentrations of Spike protein for 4 hours; and then cells were incubated for a further 20 hours at $37^{\circ} \mathrm{C}$ in ALI conditions. Cells were then washed with ice cold $\mathrm{Ca}^{+2} / \mathrm{Mg}^{+2} \mathrm{PBS}$ buffer 3 times and then incubated for an additional 24 $\mathrm{hr}$ at $4^{\circ} \mathrm{C}$ with $2 \mathrm{mg} / \mathrm{ml}$ impermeant biotinylation reagent, sulfo-NHS-S-S biotin (Thermo Scientific). Biotin-labeled cells were lysed in RIPA buffer, and biotinylated proteins were extracted using Streptavidin beads (Thermo Scientific). Levels of cell surface CFTR in the bead extract were finally analyzed by western blotting. CFTR antibodies (Clone 570 and 660) were purchased from the North Carolina Cystic Fibrosis Center (funded by the Cystic Fibrosis Foundation, Bethesda, MD).

\section{Measurement of IL-8}

Well differentiated BCi-NS1.1 cells on 12mm Snapwell inserts were treated for 4 hours apically with media or various concentrations of Original-[S1S2] Spike protein. The conditioned media in the apical side were then removed. Cells were washed with culture media and continued to incubate further for $20 \mathrm{hr}$ under ALI conditions. The concentration of IL-8 released in basolateral culture media were assayed by ELISA using the human ELISA development kits (DuoSet DY208, R\&D Systems, Minneapolis, MN, USA) according to the manufacturer's instructions.

\section{$\underline{\text { Chemicals and biologics }}$}

Digitoxin, digoxin, and ouabain were purchased from Sigma-Aldrich. Drugs and derivatives were solubilized as $4 \mathrm{mM}$ stock solutions in 100\% DMSO, and aliquots were serially diluted in the same solvent, and then into assay medium. In assays containing DMSO, the final solvent concentrations were $0.01 \%$ or less. With respect to identifying recombinant Spike protein sequences, we have adopted the World Health Organization (WHO) naming system as follows: 
(i) The Spike protein from the original SARS-CoV-2 virus, which expressed aspartic acid at position 614 (viz., [D614]) was labeled as Orig-[S1S2] Spike or Original-[S1S2] Spike. (ii) The mutant $\beta$-Spike 1.315 was labelled as $\beta$-1.315 [S1S2] Spike. Recombinant proteins produced in human T293 cells were obtained as follows: Recombinant (Original, Wuhan) SARS-CoV-2 Spike [S1+S2] protein was expressed in Baculovirus insect cells with polyhistidine tag at the C-terminal (Cat \# 40589-V08B1), and 3-1.315 [S1+S2] protein (K417N, E484K, N501Y, D614G, A701V-His; Cat \# 40589-V08811) were obtained from SinoBiologicals (Philadelphia, PA).

\section{$\underline{\text { Statistics }}$}

To determine the significance of changes in kinetic parameters of ACE2 binding to SARS-CoV-2 Spike mutants we applied least-squares regression to the linearized Eadie-Hoffstee plot of the binding data, and determined the statistical significance of the difference between the slopes (i.e., $\mathrm{K}_{\mathrm{D}}$ 's) and between the intercepts (i.e., $\mathrm{B}_{\max }$ ) using $\mathrm{R}$ or Stata statistical packages. $\mathrm{K}_{\mathrm{i}}$ values were calculated for each data point in the linear range depending on the inhibition mechanism. Except as noted, all plotted data points are the means of 3 or more independent experiments. Means \pm SE were calculated; $p<0.05$ were taken to indicate a significant difference from controls.

Acknowledgements: We gratefully acknowledge support for this project by the Cooperative Health Initiative Research Program (CHIRP), supported by NHLBI/NIH (IAA-AA-HL-14-007; H.B. Pollard, PI; Doll B., PI); and by the Consortium for Health and Military Performance (CHAMP), supported by Warfighter Readiness: Optimizing Human Performance (HU00011920047; MEM91-10314; P. Deuster, PI); and by the Center for the Study of Traumatic Stress (CSTS), supported by DOD Core Grant (HU00012120068, R. Ursano, PI.). We thank Laiman Tavedi for expert technical and administrative support. We thank Bette S. Pollard for critically reading the manuscript. We thank Alan C-Y Hsu for collegial helpful discussions.

The opinions, interpretations, conclusions and recommendations are those of the authors and are not necessarily endorsed by the U.S. Army, Department of Defense, the U.S. Government or the Uniformed Services University of the Health Sciences. The use of trade names does not constitute an official endorsement or approval of the use of such reagents or commercial hardware or software. This document may not be cited for purposes of advertisement.

Contributions: HC, HP, OE, and QY, designed experiments. HC, QY, and TC performed experiments. OE, NW, HC, TC and HP contributed to data analysis. HP, HC, OE, TC and NW, wrote the paper. All co-authors critically read the paper.

Conflict of interest: The authors declare no competing interests associated with this manuscript. 


\section{References}

1. Chen G, Wu D, Guo W, Cao Y, Huang D, Wang H, et al. Clinical and immunological features of severe and moderate coronavirus disease 2019. The Journal of clinical investigation. 2020;130(5):2620-9. doi: 10.1172/jci137244. PubMed PMID: 32217835; PubMed Central PMCID: PMCPMC7190990.

2. Zhou Z, Ren L, Zhang L, Zhong J, Xiao Y, Jia Z, et al. Heightened Innate Immune Responses in the Respiratory Tract of COVID-19 Patients. Cell Host Microbe. 2020;27(6):88390.e2. Epub 20200504. doi: 10.1016/j.chom.2020.04.017. PubMed PMID: 32407669; PubMed Central PMCID: PMCPMC7196896.

3. Huang C, Wang Y, Li X, Ren L, Zhao J, Hu Y, et al. Clinical features of patients infected with 2019 novel coronavirus in Wuhan, China. Lancet. 2020;395(10223):497-506. Epub 2020/01/28. doi: 10.1016/s0140-6736(20)30183-5. PubMed PMID: 31986264; PubMed Central PMCID: PMCPMC7159299.

4. Tisoncik JR, Korth MJ, Simmons CP, Farrar J, Martin TR, Katze MG. Into the eye of the cytokine storm. Microbiol Mol Biol Rev. 2012;76(1):16-32. Epub 2012/03/07. doi:

10.1128/mmbr.05015-11. PubMed PMID: 22390970; PubMed Central PMCID: PMCPMC3294426.

5. Channappanavar R, Perlman S. Pathogenic human coronavirus infections: causes and consequences of cytokine storm and immunopathology. Semin Immunopathol. 2017;39(5):52939. Epub 20170502. doi: 10.1007/s00281-017-0629-x. PubMed PMID: 28466096; PubMed Central PMCID: PMCPMC7079893.

6. DeDiego ML, Nieto-Torres JL, Regla-Nava JA, Jimenez-Guardeño JM, FernandezDelgado R, Fett C, et al. Inhibition of NF- $\kappa B$-mediated inflammation in severe acute respiratory syndrome coronavirus-infected mice increases survival. J Virol. 2014;88(2):913-24. Epub 2013/11/08. doi: 10.1128/jvi.02576-13. PubMed PMID: 24198408; PubMed Central PMCID: PMCPMC3911641.

7. Su CM, Wang L, Yoo D. Activation of NF- $\kappa$ B and induction of proinflammatory cytokine expressions mediated by ORF7a protein of SARS-CoV-2. Scientific reports. 2021;11(1):13464. Epub 2021/07/01. doi: 10.1038/s41598-021-92941-2. PubMed PMID: 34188167; PubMed Central PMCID: PMCPMC8242070.

8. Anand P, Puranik A, Aravamudan M, Venkatakrishnan AJ, Soundararajan V. SARSCoV-2 strategically mimics proteolytic activation of human ENaC. eLife. 2020;9. Epub 2020/05/27. doi: 10.7554/eLife.58603. PubMed PMID: 32452762; PubMed Central PMCID: PMCPMC7343387.

9. Gentzsch M, Rossier BC. A Pathophysiological Model for COVID-19: Critical Importance of Transepithelial Sodium Transport upon Airway Infection. Function (Oxf). 2020;1(2):zqaa024. Epub 20201006. doi: 10.1093/function/zqaa024. PubMed PMID: 33201937; PubMed Central PMCID: PMCPMC7662147.

10. Nalbandian A, Sehgal K, Gupta A, Madhavan MV, McGroder C, Stevens JS, et al. Postacute COVID-19 syndrome. Nature medicine. 2021;27(4):601-15. Epub 20210322. doi: 10.1038/s41591-021-01283-z. PubMed PMID: 33753937.

11. Proal AD, VanElzakker MB. Long COVID or Post-acute Sequelae of COVID-19 (PASC): An Overview of Biological Factors That May Contribute to Persistent Symptoms. Front Microbiol. 2021;12:698169. Epub 20210623. doi: 10.3389/fmicb.2021.698169. PubMed PMID: 34248921; PubMed Central PMCID: PMCPMC8260991. 
12. Chertow D, Stein S, Grazioli A, Chung J-Y, Singh M, Yinda C, et al. SARS-CoV-2 infection and persistence throughout the human body and brain. Research Square. 2021. doi: doi.org/10.21203/rs.3.rs-1139035/v1.

13. Al-Aly Z, Xie Y, Bowe B. High-dimensional characterization of post-acute sequelae of COVID-19. Nature. 2021;594(7862):259-64. Epub 20210422. doi: 10.1038/s41586-021-035539. PubMed PMID: 33887749.

14. Mainous AG, 3rd, Rooks BJ, Orlando FA. Risk of New Hospitalization Post-COVID-19 Infection for Non-COVID-19 Conditions. J Am Board Fam Med. 2021;34(5):907-13. doi: 10.3122/jabfm.2021.05.210170. PubMed PMID: 34535516.

15. Zhang Q, Lenardo MJ, Baltimore D. 30 Years of NF-kappaB: A Blossoming of Relevance to Human Pathobiology. Cell. 2017;168(1-2):37-57. Epub 2017/01/14. doi: 10.1016/j.cell.2016.12.012. PubMed PMID: 28086098; PubMed Central PMCID: PMCPmc5268070.

16. Reusch N, De Domenico E, Bonaguro L, Schulte-Schrepping J, Baßler K, Schultze JL, et al. Neutrophils in COVID-19. Front Immunol. 2021;12:652470. Epub 20210325. doi: 10.3389/fimmu.2021.652470. PubMed PMID: 33841435; PubMed Central PMCID: PMCPMC8027077.

17. Chua RL, Lukassen S, Trump S, Hennig BP, Wendisch D, Pott F, et al. COVID-19 severity correlates with airway epithelium-immune cell interactions identified by single-cell analysis. Nature biotechnology. 2020;38(8):970-9. Epub 20200626. doi: 10.1038/s41587-0200602-4. PubMed PMID: 32591762.

18. Hobbs CA, Blanchard MG, Alijevic O, Tan CD, Kellenberger S, Bencharit S, et al. Identification of the SPLUNC1 ENaC-inhibitory domain yields novel strategies to treat sodium hyperabsorption in cystic fibrosis airway epithelial cultures. American journal of physiology Lung cellular and molecular physiology. 2013;305(12):L990-11001. Epub 20131011. doi: 10.1152/ajplung.00103.2013. PubMed PMID: 24124190; PubMed Central PMCID: PMCPMC3882538.

19. Mall MA. ENaC inhibition in cystic fibrosis: potential role in the new era of CFTR modulator therapies. The European respiratory journal. 2020;56(6). Epub 20201224. doi: 10.1183/13993003.00946-2020. PubMed PMID: 32732328; PubMed Central PMCID: PMCPMC7758539.

20. Caohuy H, Eidelman O, Chen T, Liu S, Yang Q, Bera A, et al. Common cardiac medications potently inhibit ACE2 binding to the SARS-CoV-2 Spike, and block virus penetration and infectivity in human lung cells. Scientific reports. 2021. Epub Accepted for publication: 11.02.2021.

21. Caohuy H, Jozwik C, Pollard HB. Rescue of DeltaF508-CFTR by the SGK1/Nedd4-2 signaling pathway. The Journal of biological chemistry. 2009;284(37):25241-53. Epub 2009/07/21. doi: 10.1074/jbc.M109.035345. PubMed PMID: 19617352; PubMed Central PMCID: PMCPMC2757227.

22. Veit G, Avramescu RG, Chiang AN, Houck SA, Cai Z, Peters KW, et al. From CFTR biology toward combinatorial pharmacotherapy: expanded classification of cystic fibrosis mutations. Molecular biology of the cell. 2016;27(3):424-33. Epub 2016/01/30. doi: 10.1091/mbc.E14-04-0935. PubMed PMID: 26823392; PubMed Central PMCID: PMCPMC4751594.

23. Yang Q, Soltis AR, Sukumar G, Zhang X, Caohuy H, Freedy J, et al. Gene therapyemulating small molecule treatments in cystic fibrosis airway epithelial cells and patients. 
Respiratory research. 2019;20(1):290. Epub 2019/12/23. doi: 10.1186/s12931-019-1214-8. PubMed PMID: 31864360; PubMed Central PMCID: PMCPMC6925517.

24. Pereira C, Mazein A, Farinha CM, Gray MA, Kunzelmann K, Ostaszewski M, et al. CyFi-MAP: an interactive pathway-based resource for cystic fibrosis. Scientific reports. 2021;11(1):22223. Epub 20211115. doi: 10.1038/s41598-021-01618-3. PubMed PMID: 34782688; PubMed Central PMCID: PMCPMC8592983.

25. Wang H, Cebotaru L, Lee HW, Yang Q, Pollard BS, Pollard HB, et al. CFTR Controls the Activity of NF-kappaB by Enhancing the Degradation of TRADD. Cellular physiology and biochemistry : international journal of experimental cellular physiology, biochemistry, and pharmacology. 2016;40(5):1063-78. Epub 2016/12/14. doi: 10.1159/000453162. PubMed PMID: 27960153.

26. Berdiev BK, Qadri YJ, Benos DJ. Assessment of the CFTR and ENaC association. Mol Biosyst. 2009;5(2):123-7. Epub 2009/01/22. doi: 10.1039/b810471a. PubMed PMID: 19156256; PubMed Central PMCID: PMCPMC2666849.

27. Abdel Hameid R, Cormet-Boyaka E, Kuebler WM, Uddin M, Berdiev BK. SARS-CoV-2 may hijack GPCR signaling pathways to dysregulate lung ion and fluid transport. American journal of physiology Lung cellular and molecular physiology. 2021;320(3):L430-15. Epub 2021/01/13. doi: 10.1152/ajplung.00499.2020. PubMed PMID: 33434105; PubMed Central PMCID: PMCPMC7938641.

28. Stanton BA, Hampton TH, Ashare A. SARS-CoV-2 (COVID-19) and cystic fibrosis. American journal of physiology Lung cellular and molecular physiology. 2020;319(3):L408-115. Epub 20200715. doi: 10.1152/ajplung.00225.2020. PubMed PMID: 32668165; PubMed Central PMCID: PMCPMC7518058.

29. Peckham D, McDermott MF, Savic S, Mehta A. COVID-19 meets Cystic Fibrosis: for better or worse? Genes and immunity. 2020;21(4):260-2. Epub 20200701. doi: 10.1038/s41435020-0103-y. PubMed PMID: 32606316.

30. Scambler T, Jarosz-Griffiths HH, Lara-Reyna S, Pathak S, Wong C, Holbrook J, et al. ENaC-mediated sodium influx exacerbates NLRP3-dependent inflammation in cystic fibrosis. eLife. 2019;8. Epub 20190918. doi: 10.7554/eLife.49248. PubMed PMID: 31532390; PubMed Central PMCID: PMCPMC6764826.

31. Kuba K, Imai Y, Penninger JM. Angiotensin-converting enzyme 2 in lung diseases. Curr Opin Pharmacol. 2006;6(3):271-6. Epub 20060403. doi: 10.1016/j.coph.2006.03.001. PubMed PMID: 16581295; PubMed Central PMCID: PMCPMC7106490.

32. Zaika O, Mamenko M, Staruschenko A, Pochynyuk O. Direct activation of ENaC by angiotensin II: recent advances and new insights. Curr Hypertens Rep. 2013;15(1):17-24. doi: 10.1007/s11906-012-0316-1. PubMed PMID: 23180052; PubMed Central PMCID: PMCPMC3545060.

33. Guggino WB, Stanton BA. New insights into cystic fibrosis: molecular switches that regulate CFTR. Nature reviews Molecular cell biology. 2006;7(6):426-36. doi: 10.1038/nrm1949. PubMed PMID: 16723978.

34. Pollard HB, Eidelman O, Jozwik C, Huang W, Srivastava M, Ji XD, et al. De novo biosynthetic profiling of high abundance proteins in cystic fibrosis lung epithelial cells. Molecular \& cellular proteomics : MCP. 2006;5(9):1628-37. Epub 20060707. doi: 10.1074/mcp.M600091-MCP200. PubMed PMID: 16829594.

35. Pankow S, Bamberger C, Calzolari D, Martínez-Bartolomé S, Lavallée-Adam M, Balch WE, et al. $\triangle$ F508 CFTR interactome remodelling promotes rescue of cystic fibrosis. Nature. 
2015;528(7583):510-6. Epub 20151130. doi: 10.1038/nature15729. PubMed PMID: 26618866; PubMed Central PMCID: PMCPMC4826614.

36. Hsu AC-Y, Wang G, Reid AT, Veerati PC, Pathinayake PS, Daly K, et al. SARS-CoV-2 Spike protein promotes hyper-inflammatory response that can be ameliorated by Spikeantagonistic peptide and FDA-approved ER stress and MAP kinase inhibitors in vitro. . bioRxiv. 2020. doi: 10.1101/2020.09.30.317818.

37. Ouyang W, Xie T, Fang H, Gao C, Stantchev T, Clouse KA, et al. Variable Induction of Pro-Inflammatory Cytokines by Commercial SARS CoV-2 Spike Protein Reagents: Potential Impacts of LPS on In Vitro Modeling and Pathogenic Mechanisms In Vivo. International journal of molecular sciences. 2021;22(14). Epub 20210714. doi: 10.3390/ijms22147540. PubMed PMID: 34299155; PubMed Central PMCID: PMCPMC8305765.

38. Zhang H, Rostami MR, Leopold PL, Mezey JG, O'Beirne SL, Strulovici-Barel Y, et al. Expression of the SARS-CoV-2 ACE2 Receptor in the Human Airway Epithelium. American journal of respiratory and critical care medicine. 2020;202(2):219-29. doi: 10.1164/rccm.202003-0541OC. PubMed PMID: 32432483; PubMed Central PMCID: PMCPMC7365377.

39. Walters MS, Gomi K, Ashbridge B, Moore MA, Arbelaez V, Heldrich J, et al. Generation of a human airway epithelium derived basal cell line with multipotent differentiation capacity. Respiratory research. 2013;14(1):135. Epub 2013/12/05. doi: 10.1186/1465-9921-14135. PubMed PMID: 24298994; PubMed Central PMCID: PMCPMC3907041.

40. Wang G, Lou HH, Salit J, Leopold PL, Driscoll S, Schymeinsky J, et al. Characterization of an immortalized human small airway basal stem/progenitor cell line with airway regionspecific differentiation capacity. Respiratory research. 2019;20(1):196. Epub 20190823. doi: 10.1186/s12931-019-1140-9. PubMed PMID: 31443657; PubMed Central PMCID: PMCPMC6708250.

41. Zhang L, Button B, Gabriel SE, Burkett S, Yan Y, Skiadopoulos MH, et al. CFTR delivery to $25 \%$ of surface epithelial cells restores normal rates of mucus transport to human cystic fibrosis airway epithelium. PLoS biology. 2009;7(7):e1000155. Epub 2009/07/22. doi: 10.1371/journal.pbio.1000155. PubMed PMID: 19621064; PubMed Central PMCID: PMCPMC2705187.

42. Sharma M, Pampinella F, Nemes C, Benharouga M, So J, Du K, et al. Misfolding diverts CFTR from recycling to degradation: quality control at early endosomes. The Journal of cell biology. 2004;164(6):923-33. Epub 2004/03/10. doi: 10.1083/jcb.200312018. PubMed PMID: 15007060; PubMed Central PMCID: PMCPMC2172283.

43. García-Caballero A, Dang Y, He H, Stutts MJ. ENaC proteolytic regulation by channelactivating protease 2. The Journal of general physiology. 2008;132(5):521-35. Epub 20081013. doi: 10.1085/jgp.200810030. PubMed PMID: 18852303; PubMed Central PMCID: PMCPMC2571966.

44. Haerteis S, Krappitz M, Bertog M, Krappitz A, Baraznenok V, Henderson I, et al. Proteolytic activation of the epithelial sodium channel $(\mathrm{ENaC})$ by the cysteine protease cathepsin-S. Pflugers Archiv : European journal of physiology. 2012;464(4):353-65. Epub 20120805. doi: 10.1007/s00424-012-1138-3. PubMed PMID: 22864553; PubMed Central PMCID: PMCPMC3448907.

45. Gabriel SE, Brigman KN, Koller BH, Boucher RC, Stutts MJ. Cystic fibrosis heterozygote resistance to cholera toxin in the cystic fibrosis mouse model. Science (New York, NY). 1994;266(5182):107-9. doi: 10.1126/science.7524148. PubMed PMID: 7524148. 
46. Trapnell BC, Chu CS, Paakko PK, Banks TC, Yoshimura K, Ferrans VJ, et al. Expression of the cystic fibrosis transmembrane conductance regulator gene in the respiratory tract of normal individuals and individuals with cystic fibrosis. Proceedings of the National Academy of Sciences of the United States of America. 1991;88(15):6565-9. doi: 10.1073/pnas.88.15.6565. PubMed PMID: 1713683; PubMed Central PMCID: PMCPMC52127. 47. Çolak Y, Nordestgaard BG, Afzal S. Morbidity and mortality in carriers of the cystic fibrosis mutation CFTR Phe508del in the general population. The European respiratory journal. 2020;56(3). Epub 20200910. doi: 10.1183/13993003.00558-2020. PubMed PMID: 32398304. 48. Miller AC, Comellas AP, Hornick DB, Stoltz DA, Cavanaugh JE, Gerke AK, et al. Cystic fibrosis carriers are at increased risk for a wide range of cystic fibrosis-related conditions. Proceedings of the National Academy of Sciences of the United States of America. 2020;117(3):1621-7. Epub 20191227. doi: 10.1073/pnas.1914912117. PubMed PMID: 31882447; PubMed Central PMCID: PMCPMC6983448.

49. Baldassarri M, Fava F, Fallerini C, Daga S, Benetti E, Zguro K, et al. Severe COVID-19 in Hospitalized Carriers of Single CFTR Pathogenic Variants. J Pers Med. 2021;11(6). Epub 20210615. doi: 10.3390/jpm11060558. PubMed PMID: 34203982; PubMed Central PMCID: PMCPMC8232773.

50. Pollard BS, Blanco JC, Pollard JR. Classical Drug Digitoxin Inhibits Influenza Cytokine Storm, With Implications for Covid-19 Therapy. In vivo (Athens, Greece). 2020;34(6):3723-30. Epub 2020/11/05. doi: 10.21873/invivo.12221. PubMed PMID: 33144490; PubMed Central PMCID: PMCPMC7811644.

51. Hoffman BJ, Bigger J. Digitalis and Allied Cardiac Glycosides Goodman and Gilman's The Pharmacological Basis of Therapeutics Eighth Edition ed. Gilman AG, Rall TW, editors. New York: Permagon Press; page 833, 1990.

52. Mason DT, Braunwald E. Studies on digitalis: SX. Effects of ouabain on forearm vascular resistance and venous tone in normal subjects and in patients in heart failure. The Journal of clinical investigation. 1964;43(3):532-43. doi: 10.1172/jci104939. PubMed PMID: 14135505; PubMed Central PMCID: PMCPMC441947.

53. Selden R, Smith TW. Ouabain pharmacokinetics in dog and man. Determination by radioimmunoassay. Circulation. 1972;45(6):1176-82. Epub 1972/06/01. doi:

10.1161/01.cir.45.6.1176. PubMed PMID: 5032817.

54. Zeitlin PL, Diener-West M, Callahan KA, Lee S, Talbot CC, Jr., Pollard B, et al. Digitoxin for Airway Inflammation in Cystic Fibrosis: Preliminary Assessment of Safety, Pharmacokinetics, and Dose Finding. Annals of the American Thoracic Society. 2017;14(2):2209. Epub 2016/12/23. doi: 10.1513/AnnalsATS.201608-649OC. PubMed PMID: 28006108; PubMed Central PMCID: PMCPMC5427734.

55. Coates AL, Desmond K, Asher MI, Hortop J, Beaudry PH. The effect of digoxin on exercise capacity and exercising cardiac function in cystic fibrosis. Chest. 1982;82(5):543-7. Epub 1982/11/01. PubMed PMID: 7128221.

56. Moss AJ, Finkelstein S, Crudup C, Young GA, Dooley RR, Osher AB. Absorption of digoxin in children with cystic fibrosis. The Journal of pediatrics. 1975;86(2):295-7. Epub 1975/02/01. PubMed PMID: 1111698.

57. Selzer A, Hultgren HN, Ebnother CL, Bradley HW, Stone AO. Efect of digoxin on the circulation in normal man. Br Heart J. 1959;21(3):335-42. doi: 10.1136/hrt.21.3.335. PubMed PMID: 14444797; PubMed Central PMCID: PMCPMC1017589. 
58. Williams MH, Jr., Zohman LR, Ratner AC. Hemodynamic effects of cardiac glycosides on normal human subjects during rest and exercise. J Appl Physiol. 1958;13(3):417-21. doi: 10.1152/jappl.1958.13.3.417. PubMed PMID: 13587425.

59. Paz Ocaranza M, Riquelme JA, García L, Jalil JE, Chiong M, Santos RAS, et al. Counterregulatory renin-angiotensin system in cardiovascular disease. Nat Rev Cardiol. 2020;17(2):11629. Epub 20190819. doi: 10.1038/s41569-019-0244-8. PubMed PMID: 31427727; PubMed Central PMCID: PMCPMC7097090.

60. Hanukoglu I, Hanukoglu A. Epithelial sodium channel (ENaC) family: Phylogeny, structure-function, tissue distribution, and associated inherited diseases. Gene. 2016;579(2):95132. Epub 20160107. doi: 10.1016/j.gene.2015.12.061. PubMed PMID: 26772908; PubMed Central PMCID: PMCPMC4756657.

61. Mall M, Grubb BR, Harkema JR, O'Neal WK, Boucher RC. Increased airway epithelial $\mathrm{Na}+$ absorption produces cystic fibrosis-like lung disease in mice. Nature medicine. 2004;10(5):487-93. Epub 20040411. doi: 10.1038/nm1028. PubMed PMID: 15077107.

62. Enuka Y, Hanukoglu I, Edelheit O, Vaknine H, Hanukoglu A. Epithelial sodium channels $(\mathrm{ENaC})$ are uniformly distributed on motile cilia in the oviduct and the respiratory airways. Histochem Cell Biol. 2012;137(3):339-53. Epub 20111230. doi: 10.1007/s00418-011-0904-1. PubMed PMID: 22207244.

63. Rossier BC, Stutts MJ. Activation of the epithelial sodium channel (ENaC) by serine proteases. Annu Rev Physiol. 2009;71:361-79. doi: 10.1146/annurev.physiol.010908.163108. PubMed PMID: 18928407.

64. Kleyman TR, Carattino MD, Hughey RP. ENaC at the cutting edge: regulation of epithelial sodium channels by proteases. The Journal of biological chemistry. 2009;284(31):20447-51. Epub 20090428. doi: 10.1074/jbc.R800083200. PubMed PMID: 19401469; PubMed Central PMCID: PMCPMC2742807.

65. Heurich A, Hofmann-Winkler H, Gierer S, Liepold T, Jahn O, Pöhlmann S. TMPRSS2 and ADAM17 cleave ACE2 differentially and only proteolysis by TMPRSS2 augments entry driven by the severe acute respiratory syndrome coronavirus spike protein. J Virol.

2014;88(2):1293-307. Epub 20131113. doi: 10.1128/jvi.02202-13. PubMed PMID: 24227843; PubMed Central PMCID: PMCPMC3911672.

66. Hoffmann M, Kleine-Weber H, Schroeder S, Krüger N, Herrler T, Erichsen S, et al. SARS-CoV-2 Cell Entry Depends on ACE2 and TMPRSS2 and Is Blocked by a Clinically Proven Protease Inhibitor. Cell. 2020;181(2):271-80.e8. Epub 2020/03/07. doi: 10.1016/j.cell.2020.02.052. PubMed PMID: 32142651; PubMed Central PMCID: PMCPMC7102627.

67. Cantin AM, Hanrahan JW, Bilodeau G, Ellis L, Dupuis A, Liao J, et al. Cystic fibrosis transmembrane conductance regulator function is suppressed in cigarette smokers. American journal of respiratory and critical care medicine. 2006;173(10):1139-44. Epub 20060223. doi: 10.1164/rccm.200508-1330OC. PubMed PMID: 16497995.

68. Rab A, Rowe SM, Raju SV, Bebok Z, Matalon S, Collawn JF. Cigarette smoke and CFTR: implications in the pathogenesis of COPD. American journal of physiology Lung cellular and molecular physiology. 2013;305(8):L530-41. Epub 2013/08/13. doi: 10.1152/ajplung.00039.2013. PubMed PMID: 23934925; PubMed Central PMCID: PMCPMC3798775.

69. Fernandez Fernandez E, De Santi C, De Rose V, Greene CM. CFTR dysfunction in cystic fibrosis and chronic obstructive pulmonary disease. Expert review of respiratory medicine. 
2018;12(6):483-92. Epub 2018/05/12. doi: 10.1080/17476348.2018.1475235. PubMed PMID: 29750581.

70. Courville CA, Tidwell S, Liu B, Accurso FJ, Dransfield MT, Rowe SM. Acquired defects in CFTR-dependent beta-adrenergic sweat secretion in chronic obstructive pulmonary disease. Respiratory research. 2014;15:25. Epub 2014/02/27. doi: 10.1186/1465-9921-15-25. PubMed PMID: 24568560; PubMed Central PMCID: PMCPMC4015030.

71. Sloane PA, Shastry S, Wilhelm A, Courville C, Tang LP, Backer K, et al. A pharmacologic approach to acquired cystic fibrosis transmembrane conductance regulator dysfunction in smoking related lung disease. PloS one. 2012;7(6):e39809. Epub 2012/07/07. doi: 10.1371/journal.pone.0039809. PubMed PMID: 22768130; PubMed Central PMCID: PMCPMC3387224.

72. Raju SV, Jackson PL, Courville CA, McNicholas CM, Sloane PA, Sabbatini G, et al. Cigarette smoke induces systemic defects in cystic fibrosis transmembrane conductance regulator function. American journal of respiratory and critical care medicine.

2013;188(11):1321-30. Epub 2013/09/18. doi: 10.1164/rccm.201304-0733OC. PubMed PMID: 24040746; PubMed Central PMCID: PMCPMC3919073.

73. Londino JD, Lazrak A, Noah JW, Aggarwal S, Bali V, Woodworth BA, et al. Influenza virus M2 targets cystic fibrosis transmembrane conductance regulator for lysosomal degradation during viral infection. FASEB journal : official publication of the Federation of American Societies for Experimental Biology. 2015;29(7):2712-25. Epub 2015/03/22. doi: 10.1096/fj.14268755. PubMed PMID: 25795456; PubMed Central PMCID: PMCPMC4478808.

74. Londino JD, Lazrak A, Collawn JF, Bebok Z, Harrod KS, Matalon S. Influenza virus infection alters ion channel function of airway and alveolar cells: mechanisms and physiological sequelae. American journal of physiology Lung cellular and molecular physiology.

2017;313(5):L845-158. Epub 20170803. doi: 10.1152/ajplung.00244.2017. PubMed PMID: 28775098; PubMed Central PMCID: PMCPMC5792181.

75. Okuda K, Dang H, Kobayashi Y, Carraro G, Nakano S, Chen G, et al. Secretory Cells Dominate Airway CFTR Expression and Function in Human Airway Superficial Epithelia. American journal of respiratory and critical care medicine. 2021;203(10):1275-89. doi: 10.1164/rccm.202008-31980C. PubMed PMID: 33321047; PubMed Central PMCID: PMCPMC8456462.

76. Caohuy H, Yang Q, Eudy Y, Ha TA, Xu AE, Glover M, et al. Activation of 3phosphoinositide-dependent kinase 1 (PDK1) and serum- and glucocorticoid-induced protein kinase 1 (SGK1) by short-chain sphingolipid C4-ceramide rescues the trafficking defect of DeltaF508-cystic fibrosis transmembrane conductance regulator (DeltaF508-CFTR). The Journal of biological chemistry. 2014;289(52):35953-68. Epub 2014/11/12. doi:

10.1074/jbc.M114.598649. PubMed PMID: 25384981; PubMed Central PMCID: PMCPmc4276863. 
Table 1. Inhibition constants for $\alpha$ and $\beta$ Spike effects on CFTR channels and CFTR protein, and for binding constants for ACE2.

\begin{tabular}{|c|c|c|c|}
\hline Spike Variant & $\begin{array}{c}K_{i}, C F T R \\
\text { channel }\left(R^{2}\right) \\
\text { ng Spike/ml }\end{array}$ & $\begin{array}{c}\mathrm{K}_{\mathrm{i}}, \mathrm{CFTR} \\
\text { protein }\left(\mathrm{R}^{2}\right) \\
\mathrm{ng} \text { Spike } / \mathrm{ml}\end{array}$ & $\begin{array}{c}\mathrm{K}_{\mathrm{D}}, \mathrm{ACE} 2\left(\mathrm{R}^{2}\right) \\
\mathrm{ng} \text { ACE2 } / \mathrm{ml}\end{array}$ \\
\hline $\begin{array}{l}\text { Original- } \\
\text { [S1S2] }\end{array}$ & $446(0.9898)$ & $399(0.9842)$ & $318(0.9960)$ \\
\hline $\begin{array}{l}\beta-1.315 \\
{[S 1 S 2]}\end{array}$ & $210(0.9956)$ & 193 (0.9590) & $147(0.9962)$ \\
\hline $\begin{array}{l}\text { Ratio,\%: } \\
\text { Original/ } \beta-1.315\end{array}$ & $(47 \%)$ & $(48 \%)$ & $(45 \%)$ \\
\hline
\end{tabular}




\section{Figure 1.}

a
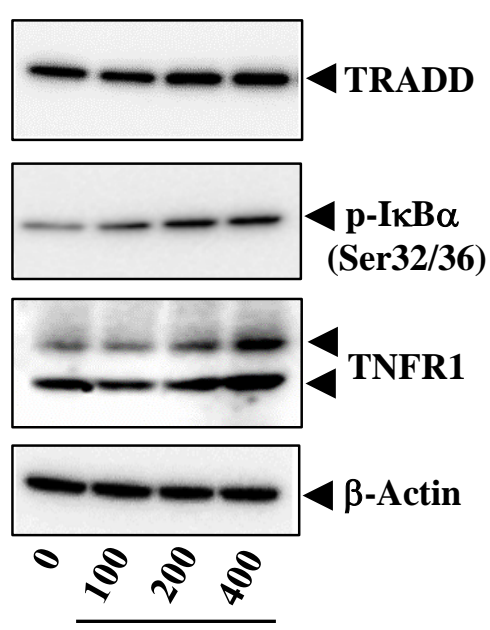

Orig [S1S2] Spike, ng/mL b

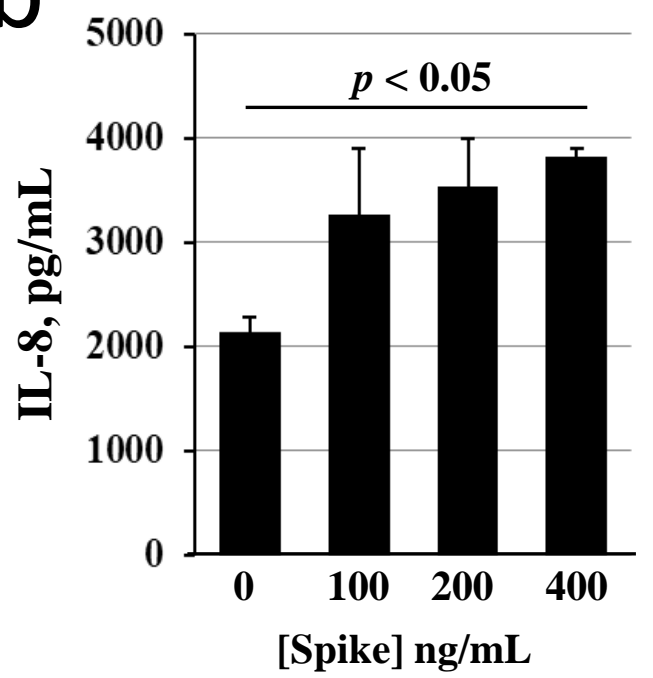

Figure 1. Effects of SARS-CoV-2 [S1S2] Spike on pro-Inflammatory TNF $\alpha / N F k B$ signaling proteins and IL-8 expression in differentiated BCi.NS1.1 (d-BCi) epithelia. The apical surface of the differentiated epithelium was treated with increasing concentrations of Original-[S1S2] Spike protein for 4 hours in submerged conditions, washed and then incubated for an additional 20 hours in ALI conditions. (a). TRADD, TNFR1 and p-IKB $\alpha$ increase in a Spike concentration-dependent manner. (b). IL-8 expression significantly increases as a function of increasing concentration of Spike protein. $(\mathrm{N}=3$ independent experiments; $p<0.05$ taken as significantly different from control. 
Figure 2.

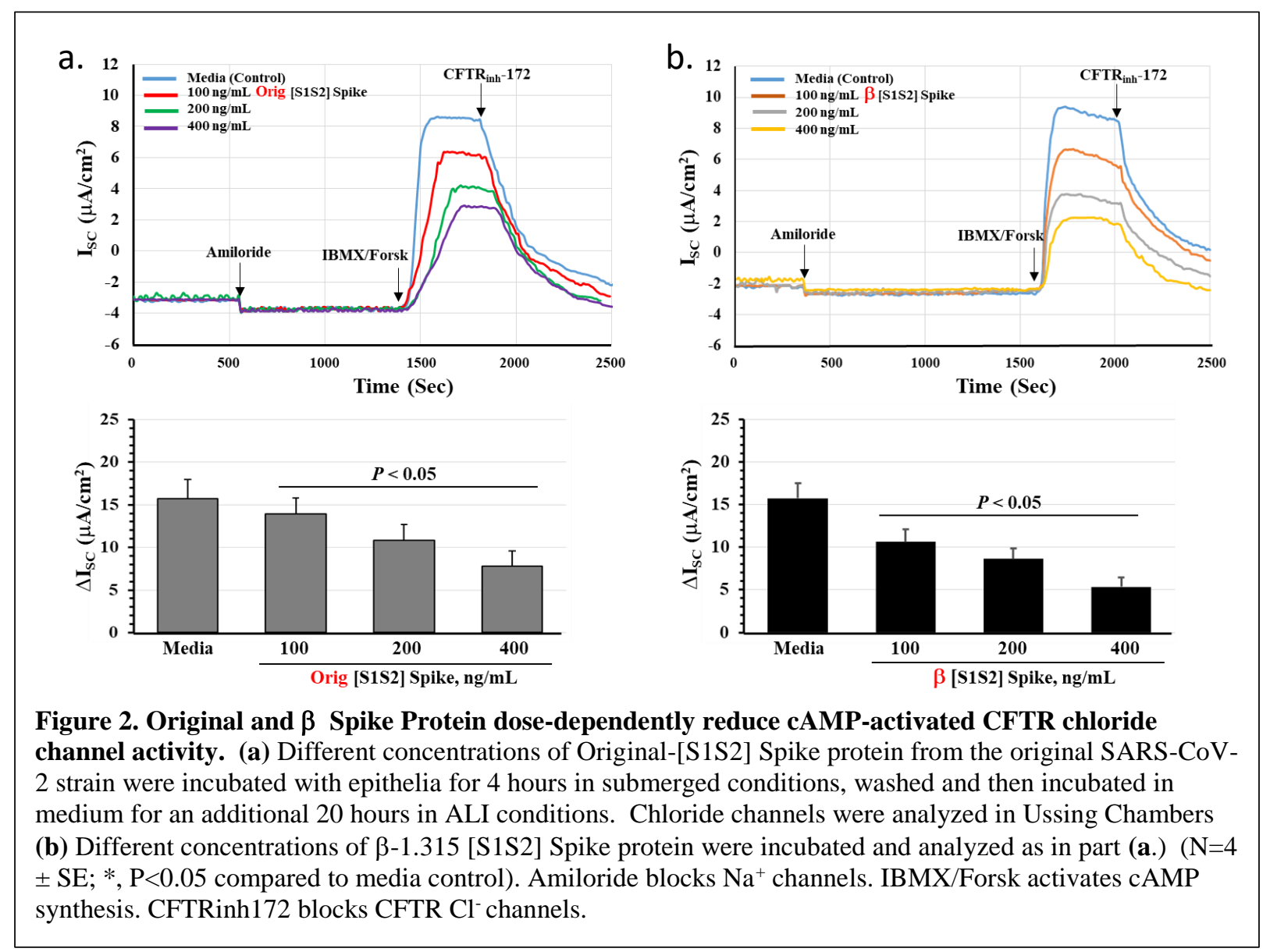




\section{Figure 3}

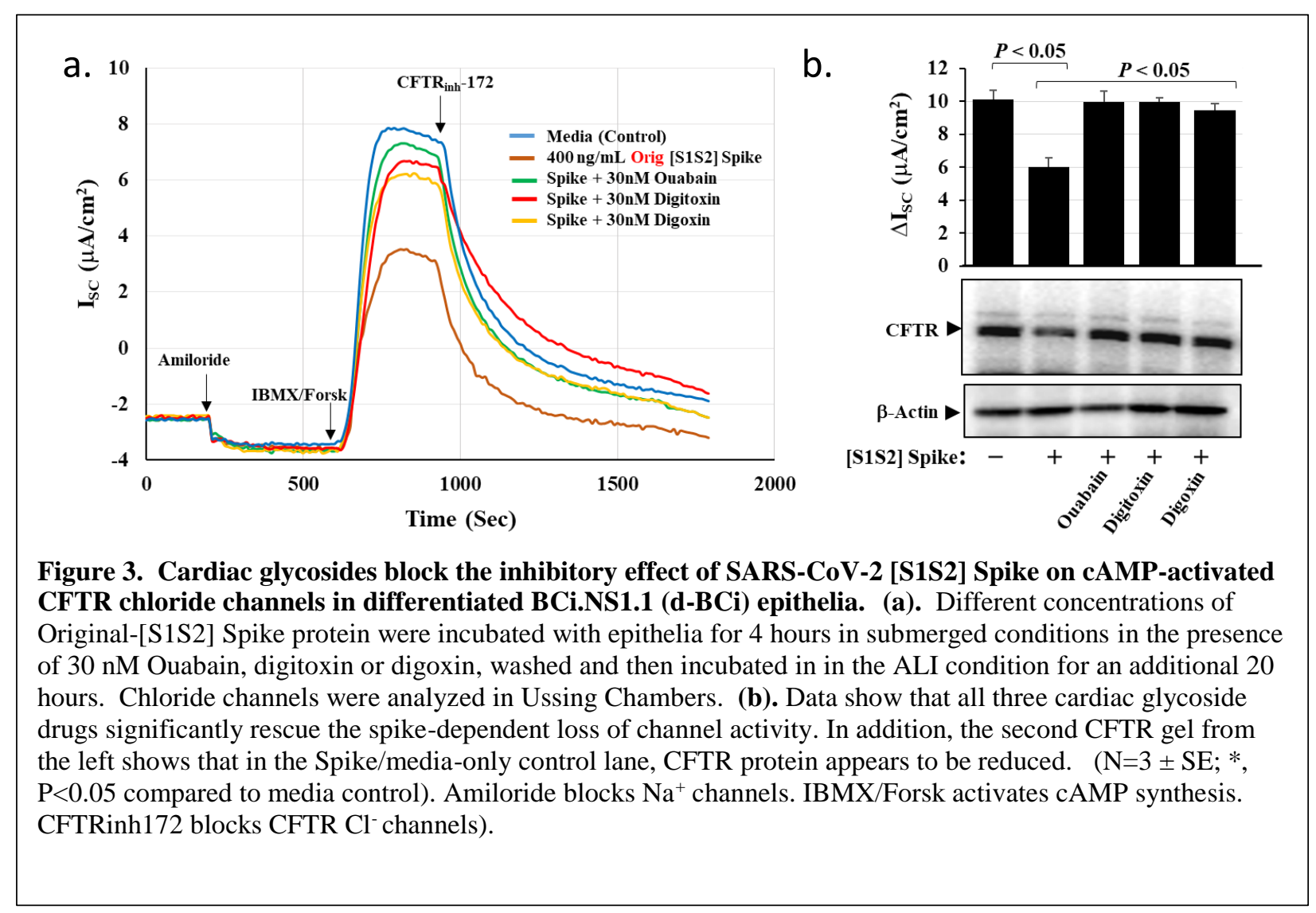




\section{Figure 4}
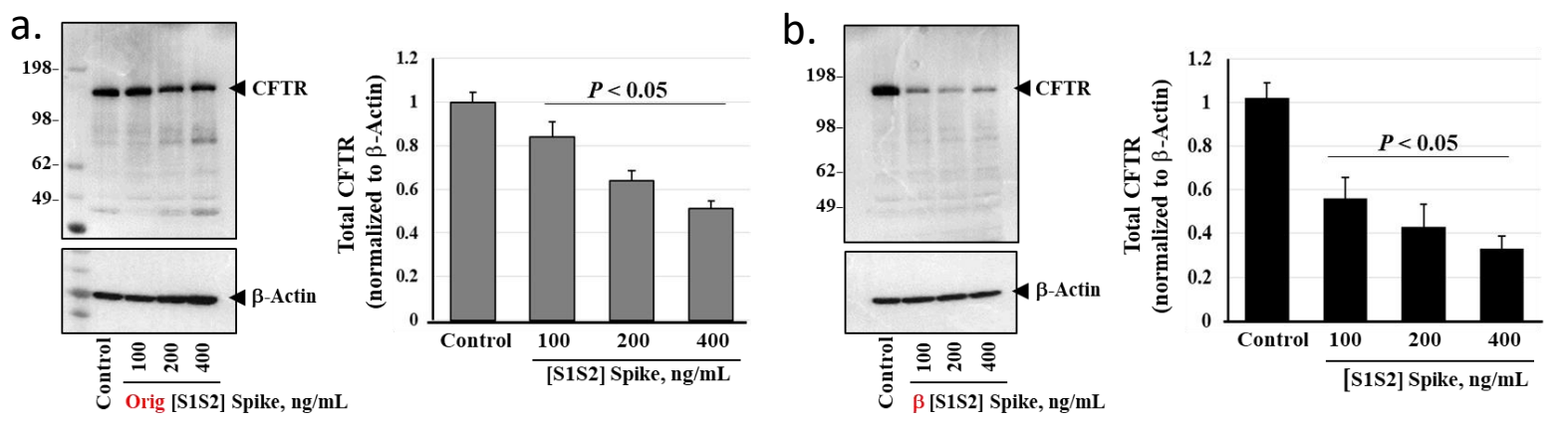

Figure 4. Original-[S1S2] Spike and $\beta-1.315$ [S1S2] Spike proteins inhibit apical and total CFTR protein expression in differentiated BCi.NS1.1 (d-BCi) epithelia. (a) Different concentrations of Original-[S1S2] Spike protein were incubated with epithelia for 4 hours in submerged conditions, washed and then incubated in medium for an additional 20 hours in ALI conditions. Total CFTR protein in epithelia were measured by Western blot. (b) Different concentrations of $\beta-1.315$ [S1S2] Spike protein were incubated and analyzed as in part (a.) ( $\mathrm{N}=4 \pm \mathrm{SE} ; *, p<0.05$ compared to media control).

Figure 5.

a.

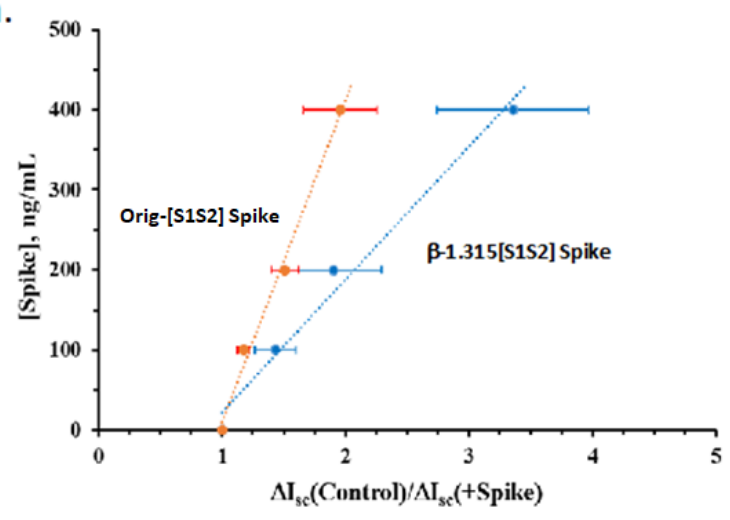

b.

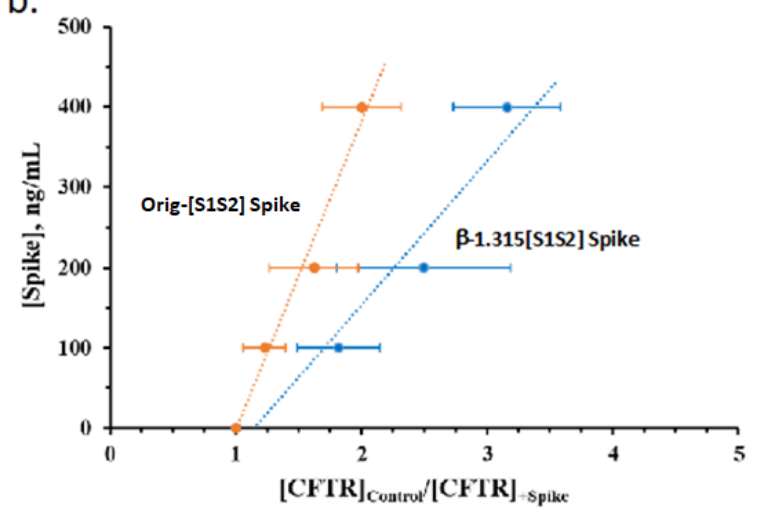

Figure 5. $\mathrm{K}_{\mathrm{i}}$ values for cAMP-dependent CFTR chloride channel activity and for CFTR protein levels as a consequence of exposure of differentiated cultures to Original or $\boldsymbol{\beta}$ Spike proteins. (a) CFTR Channel conductance as a function of Original and $\beta$ Spike concentrations. $K_{i}$ for Original-[S1S2] Spike is $448 \mathrm{ng} / \mathrm{ml}$ $\left(\mathrm{R}^{2}=0.9898\right)$. $\mathrm{K}_{\mathrm{i}}$ for $\beta-$ Spike is $210 \mathrm{ng} / \mathrm{ml}\left(\mathrm{R}^{2}=0.9956\right)$. (b). CFTR protein level as a function of Original and $\beta$ Spike concentrations. $K_{i}$ for Original-Spike is $399 \mathrm{ng} / \mathrm{ml}\left(\mathrm{R}^{2}=0.9842\right) . K_{i}$ for $\beta$-Spike is $193 \mathrm{ng} / \mathrm{ml}\left(\mathrm{R}^{2}=\right.$ 0.9590). Graphs are derived from the Eadie-Hoffstee equation. $\mathrm{K}_{\mathrm{i}}$ values are the slopes of the straight lines. Points are averages from $\mathrm{N}=4 \pm \mathrm{SE}$ independent experiments. 


\section{Figure 6.}
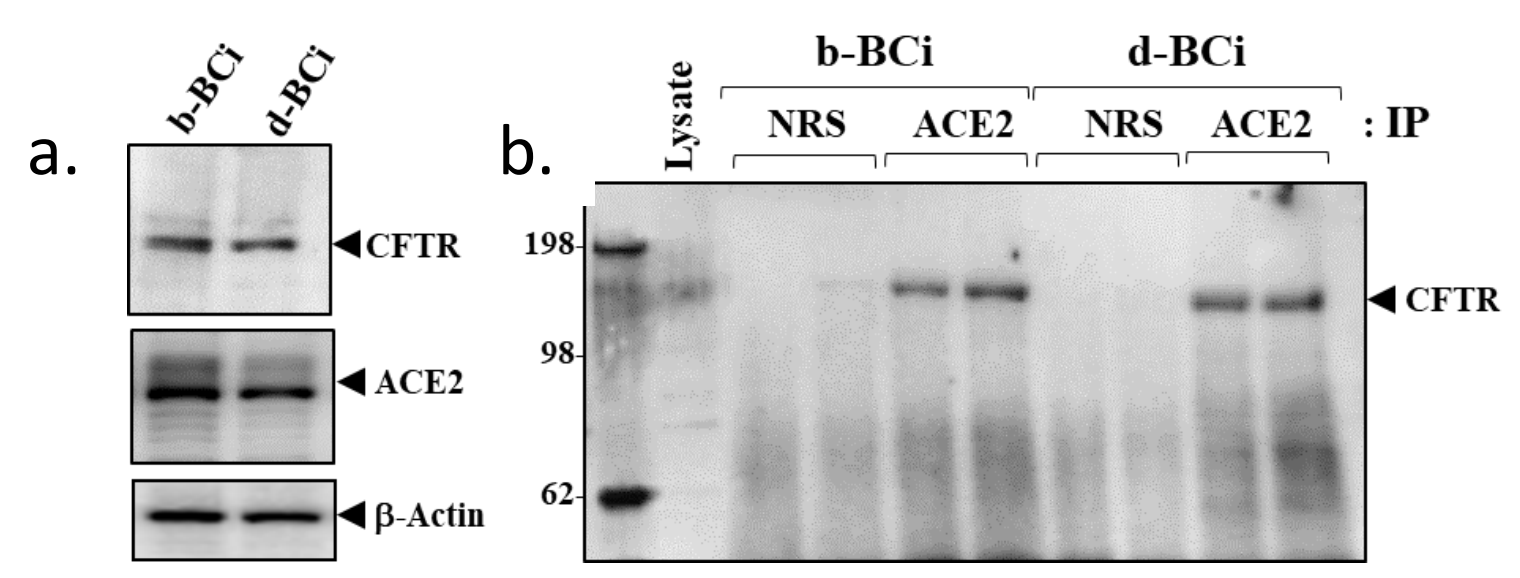

Figure 6. ACE2 binds CFTR in basal (b-BCi) cells and differentiated (d-BCi) epithelia. (a) Total CFTR and ACE2 levels in basal (b-BCi) and differentiated (d-BCi) epithelia. (b) CFTR bound to ACE2 in basal (b$\mathrm{BCi})$ and differentiated (d-BCi) epithelia. 


\section{Figure 7}
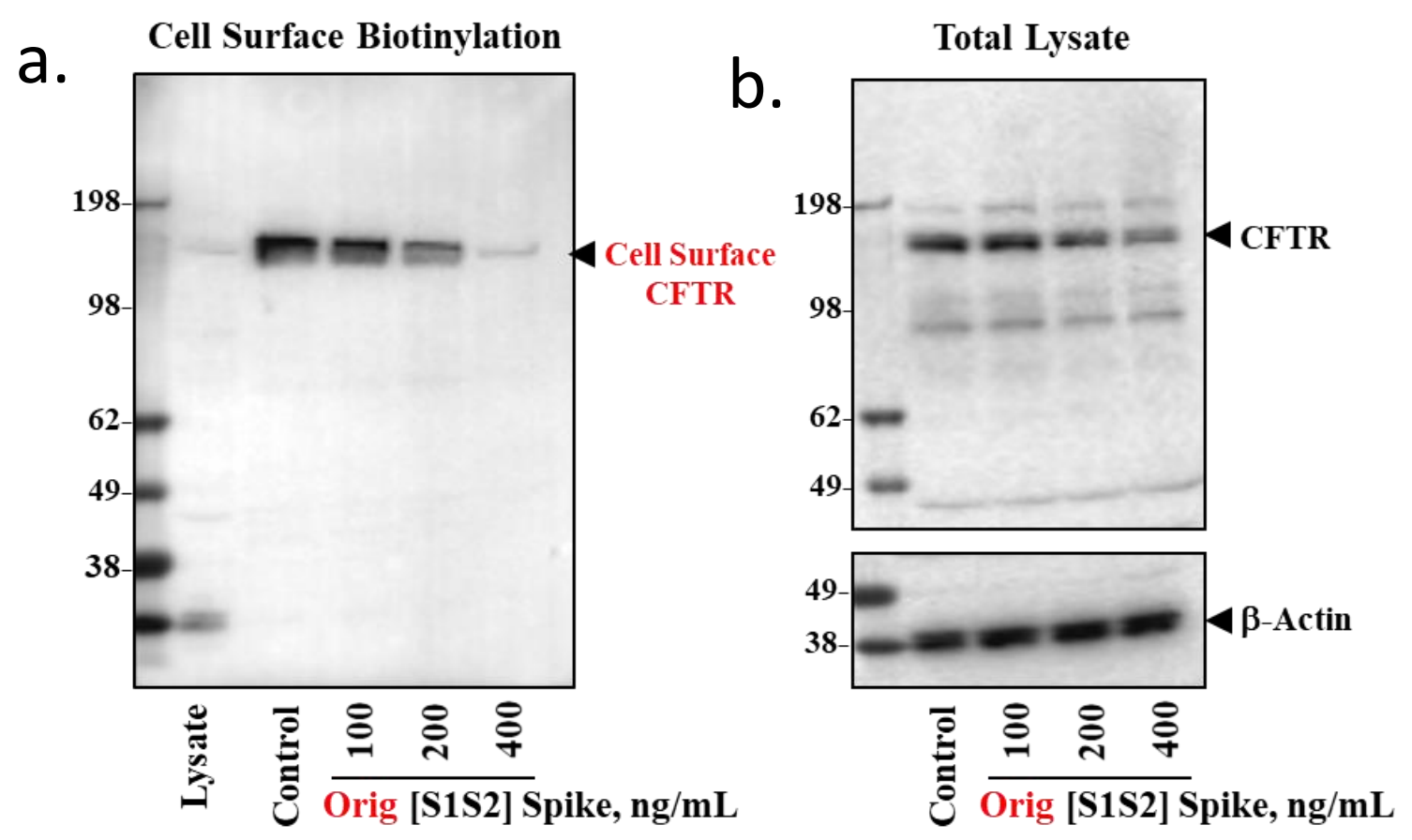

Figure 7. Effects of SARS-CoV-2 [S1S2] Spike on the endosomal recycling of cell surface CFTR protein expression in differentiated BCi-NS1.1 (d-BCi) Cells. (a) Endosomal recycling of cell surface CFTR by cell surface biotinylation as a function of exposure to increasing concentrations of Original-[S1S2] Spike protein. Epithelia were exposed to different concentrations of Spike protein for four hours; washed and incubated for a further 20 hours; then washed with ice-cold $\mathrm{Ca}^{2+} / \mathrm{Mg}^{2+}$ PBS buffer 3 times; then incubated with $2 \mathrm{mg} / \mathrm{ml}$ impermeant biotinylation reagent sulfo-NHS-S-S biotin for 24 hours at $4^{\circ} \mathrm{C}$ before extraction with Strepavidin beads and assay by Western blot for CFTR. (b) Total lysates from the experiment in Part a. Note that total CFTR protein is also in decline as a function of concentration increases in original-[S1S2] Spike. This is consistent with the concept in Supplemental Figure S3, showing most CFTR flows to the plasma membrane through the TGN, and is endosomally recycled, either to the lysosome, the TGN or back to the plasma membrane. . 


\section{Figure 8.}

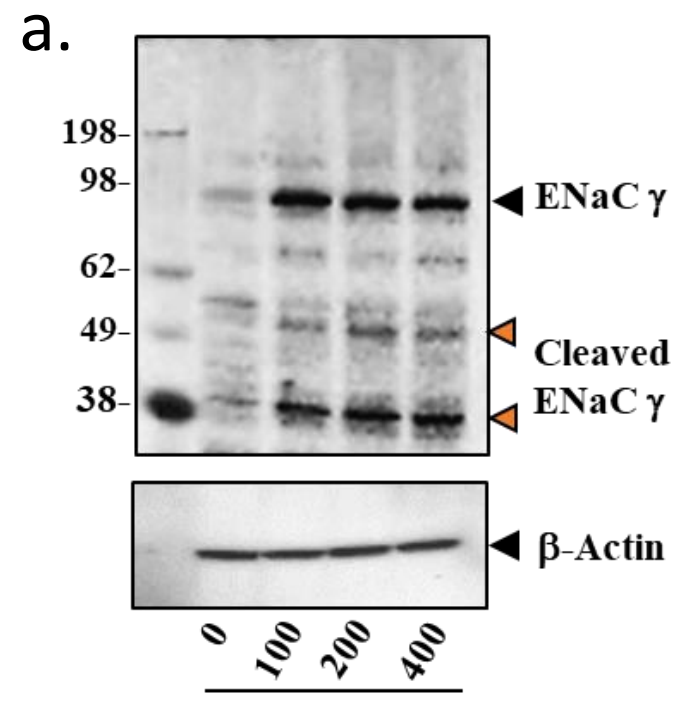

Orig [S1S2] Spike, ng/mL

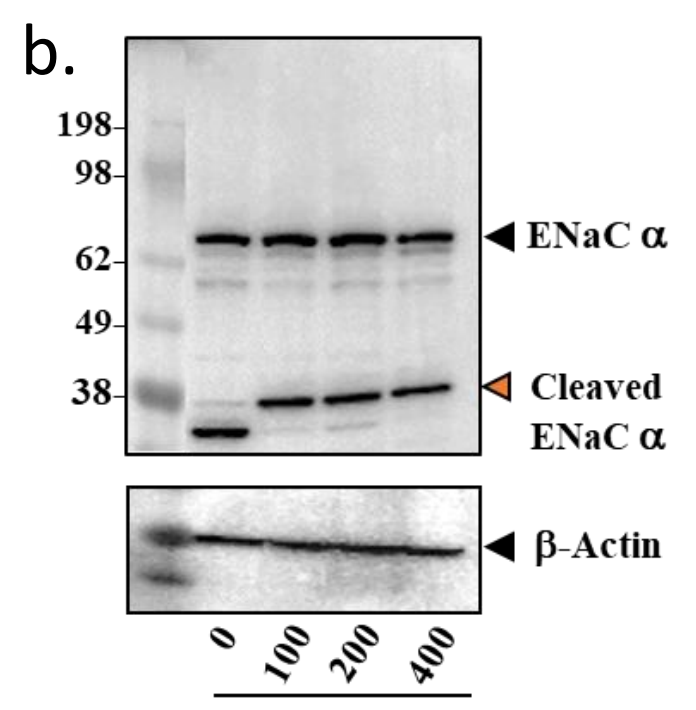

Orig [S1S2] Spike, ng/mL

Figure 8. SARS-CoV-2 [S1S2] Spike Increases proteolytic activation of $\alpha$ and $\gamma$ ENAC Subunits in Differentiated BCi-NS1.1 Cells. (a) After Ussing chamber analyses, cells were washed with PBS and lysed in RIPA buffer supplemented with the anti-protease/phosphatase cocktail. Equivalent amounts of lysates ( $50 \mu \mathrm{g} / \mathrm{sample}$ ) were electrophoresed on $4-12 \%$ or $4-20 \%$ gradient gels (Invitrogen), transferred to PVDF membranes, and membranes were probed with $\beta$-Actin antibody (Sigma) and an antibody against $\gamma \mathrm{ENaC}$. (b) Epithelia were managed as described for Part a, and then probed with an antibody against $\alpha \mathrm{ENaC}$. 


\section{Supplemental Data for}

\section{Inflammation in the COVID-19 airway is due to inhibition of CFTR signaling by the SARS-CoV-2 Spike protein}

Hung Caohuy 1,2, , Ofer Eidelman 1,2, , Tinghua Chen 1,2,3, Qingfeng Yang 1, 4 , Nathan I. Walton 1,2,3, Harvey B. Pollard 1,2,3,

1. Department of Anatomy, Physiology and Genetics, Uniformed Services University School of Medicine, Uniformed Services University of the Health Sciences, Bethesda, MD 20814.

2. Collaborative Health Initiative Research Program (CHIRP), Uniformed Services University of the Health Sciences, Bethesda, MD 20814

3. Consortium for Health and Military Performance (CHAMP), Uniformed Services University of the Health Sciences, Bethesda, MD 20814, Uniformed Services University of the Health Sciences, Bethesda, MD 20814

4. Center for the Study of Traumatic Stress (CSTS), and Department of Psychiatry, Uniformed Services University of the Health Sciences, Bethesda, MD 20814

${ }^{*}$ Communications:

Harvey B. Pollard, M.D., Ph.D.

Department of Anatomy, Physiology and Genetics

Uniformed Services University School of Medicine,

Uniformed Services University of the Health Sciences, Bethesda, MD 20814

T: 301-295-3200; Email: harvey.pollard@usuhs.edu 


\section{Supplemental Methods}

Enzyme Linked Immunosorbant Assay (ELISA) for interaction between Spike proteins and ACE2

Purified recombinant SARS-CoV-2 Spike proteins were individually dissolved in coating buffer (16 $\mathrm{mM} \mathrm{Na}_{2} \mathrm{CO}_{3}, 34 \mathrm{mM} \mathrm{NaHCO}_{3}, \mathrm{pH}$ 9.6) at a concentration of $2 \mu \mathrm{g} / \mathrm{ml}$ Spike protein. This solution, in $100 \mu \mathrm{L}$ aliquots, was then added to wells of Costar 96 well plates (Corning, Corning, NY; Catalog \# 2592) and incubated overnight at $4^{\circ} \mathrm{C}$. The next day, wells were washed 3 times in Phosphate Buffered Saline with 0.05\% Tween 20 (PBST) at room temperature. Wells were then blocked with $300 \mu \mathrm{L}$ Blocking Buffer (0.5\% Bovine Serum Albumin (BSA), dissolved in PBST) for two hours at $37^{\circ} \mathrm{C}$. Wells were then washed 3 times in PBST at room temperature $\left(68^{\circ} \mathrm{F}\right)$. When cardiac glycosides were to be added, they were dissolved in Reagent Diluent (0.5\% BSA in PBST), added in $100 \mu \mathrm{L}$ volumes to each well, and incubated at $37^{\circ} \mathrm{C}$ overnight. Further steps were as described in our recent publication [20]. The final results are given as averages \pm Standard Errors of all independent experiments.

\section{$\underline{\text { Recombinant proteins and antibodies }}$}

Recombinant proteins produced in human T293 cells were obtained as follows:

Recombinant (exodomain) Human Angiotensin Converting Enzyme 2 (ACE2) (Cat \# 230-30165; lot 04U0620TW) was purchased from RayBiotech (Peachtree Cornewrs, GA, 30092). Human ACE2 Biotinylated Antibody (Cat \# BAF933) was obtained from R\&D Systems (Minneapolis, $\mathrm{MN}, 55413)$. 


\section{Supplemental Figures}

\section{Supplemental Figure S1}

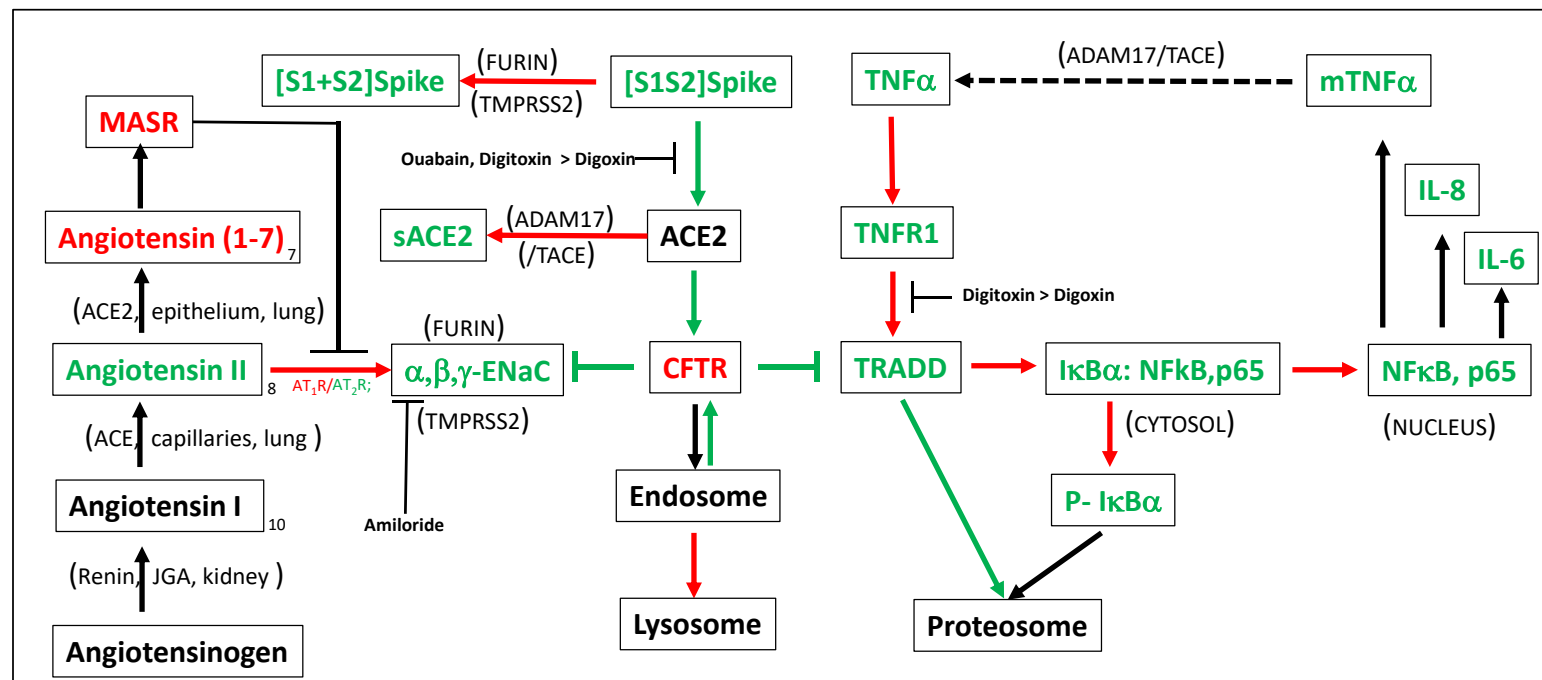

Figure S1. Inactivation of CFTR by Spike protein activates both NFkB,p65 and $\alpha, \beta, \gamma$ ENaC

signaling. Under baseline conditions CFTR tonically suppresses ENaC and TRADD. However, upon addition of [S1S2] Spike, CFTR is dose-dependently reduced by failure to be recovered from endosomal recycling (this paper). In the absence of CFTR, TRADD is no longer constitutively directed to the

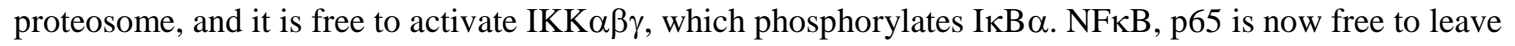
the cytosol and enter the nucleus. Cytokines and chemokines such as IL-6, IL-8 and mTNF $\alpha$ are then expressed. Membrane-bound TNF $\alpha$ (mTNF $\alpha$ ) is converted to soluble sTNF $\alpha / T N F \alpha$ by ADAM17/TACE). ADAM17/TACE also converts membrane bound mACE2 to soluble sACE2. Cardiac glycoside drugs ouabain, digitoxin and digoxin are potent competitive inhibitors of Spike:ACE2 binding (Caohuy H. et al, Scientific Reports,2021). Digitoxin separately blocks interactions in the host between the TNF $\alpha / T N F R 1$ complex and TRADD (Yang Q et al, PNAS, 2005). In the absence of CFTR, ENaC is also proteolytically activated by FURIN and TMPRSS2 (this paper). In preparation for penetration into the target cell, the same proteases cleave Spike at the S1S2 junction. Color code: red = elevated; green $=$ reduced; black $=$ no known change. 


\section{Supplemental Figure S2}
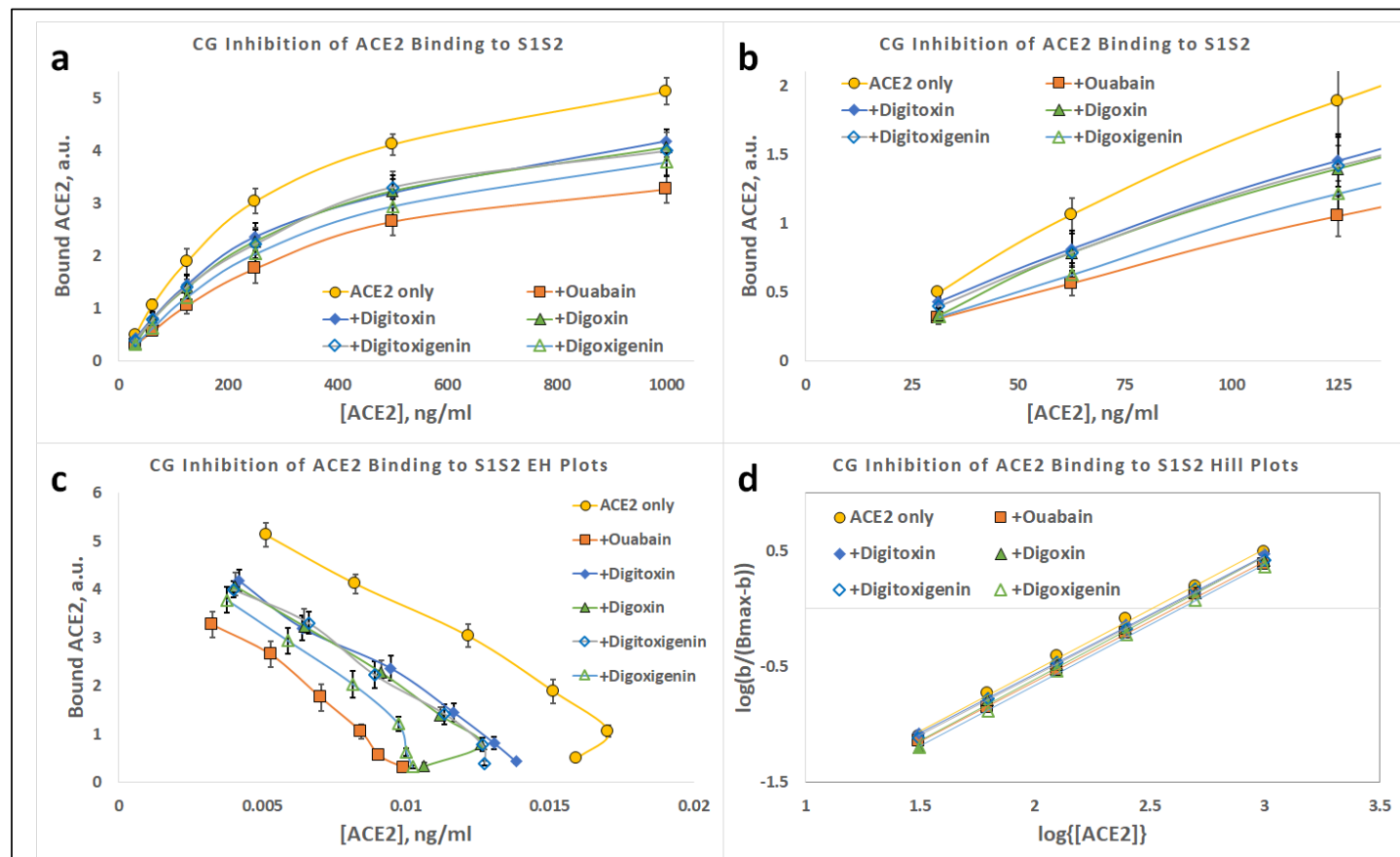

Figure S2. Binding of ACE2 to Original-Spike protein. (a) Substrate-Binding plots for ACE2 binding to Original [D614] $\alpha$-Spike in presence and absence of cardiac glycoside drugs. (b) SubstrateBinding plot for lower concentrations of ACE2. Note concave-down structure at low binding levels. (c) Eadie-Hoffstee plots of data in Part (a). (d) Hill plots for data in Part (a). Each point is the average $\pm \mathrm{SE}$ for $\mathrm{N}=5-6$ independent experiments.

\begin{tabular}{|l|l|l|l|l|l|}
\hline $\begin{array}{l}\text { Original- } \\
\text { Spike_1000 } \\
\text { ng/well }\end{array}$ & $\mathbf{k 1 / 2}$ & $\mathbf{B m a x}$ & $\mathbf{R s q}$ & $\mathbf{n H}$ & $\mathbf{n H + -}$ \\
\hline ACE2 only & 318 & 6.8 & 0.996 & 1.050 & 0.023 \\
\hline $30 \mathrm{nM}$ digitoxin & 353 & 5.6 & 0.991 & 1.020 & 0.014 \\
\hline $\begin{array}{l}30 \mathrm{nM} \\
\text { digitoxigenin }\end{array}$ & 362 & 5.5 & 0.989 & 1.023 & 0.020 \\
\hline $30 \mathrm{nM}$ digoxin & 373 & 5.6 & 0.998 & 1.061 & 0.033 \\
\hline $\begin{array}{l}30 \mathrm{nM} \\
\text { digoxigenin }\end{array}$ & 426 & 5.4 & 0.996 & 1.046 & 0.017 \\
\hline $30 \mathrm{nM}$ ouabain & 398 & 4.6 & 0.985 & 1.034 & 0.018 \\
\hline
\end{tabular}




\section{Supplemental Figure S3}

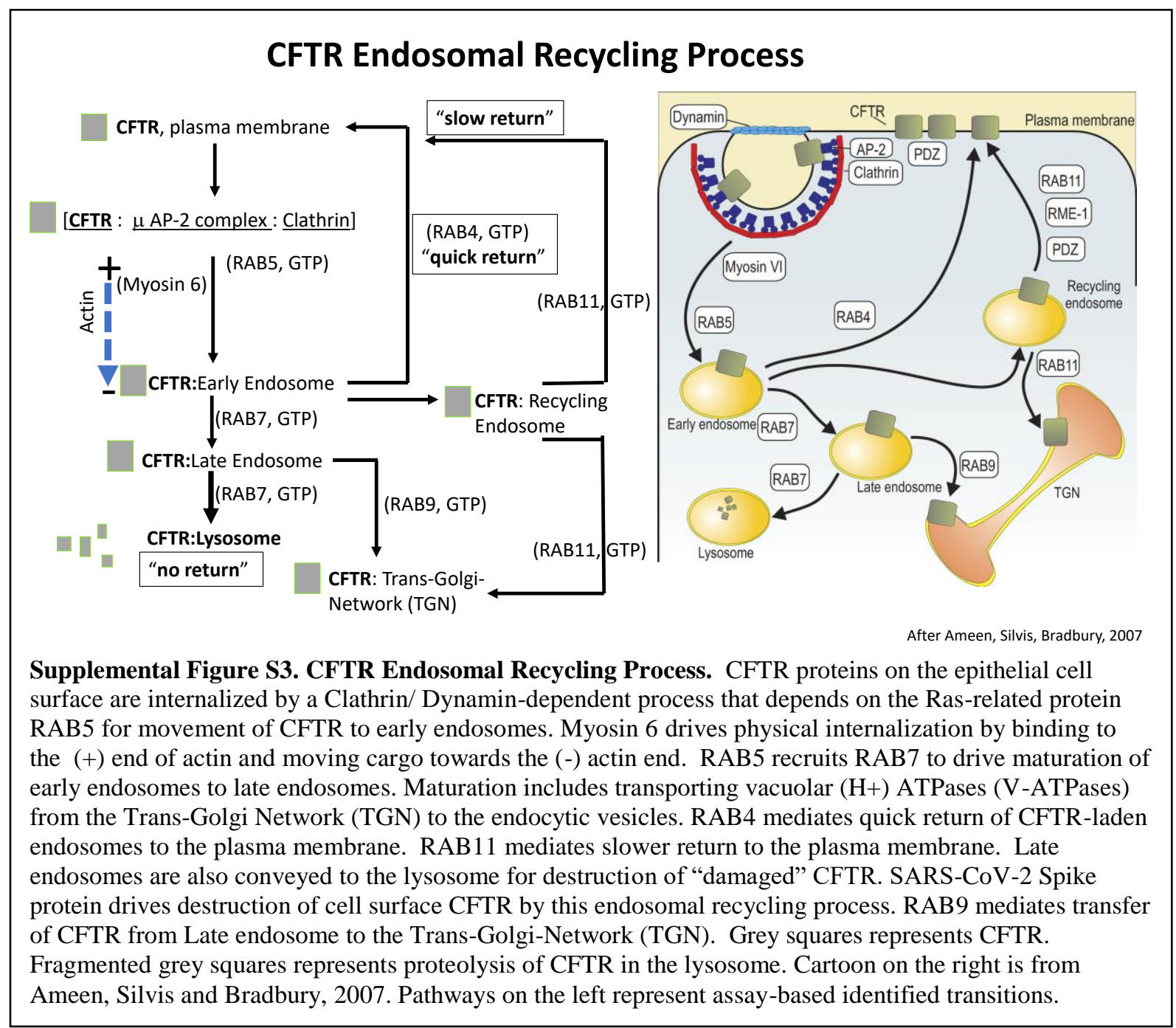

